\title{
AN INTERNATIONAL VIEW OF NATIONAL BIOLOGICAL SURVEYS ${ }^{1}$
}

\author{
Jorge Soberón ${ }^{2,3}$, Jorge Llorente ${ }^{2,4}$, \\ and Hesiquio Benítez $z^{2.4}$
}

\begin{abstract}
Museums and herbaria in industrialized countries hold a huge amount of data in the form of labels associated with specimens collected in developing countries. These data represent a significant part of the existing information on biodiversity available for most developing countries. In this paper we first discuss the usefulness of the label information, providing some examples from Mexico. Acquiring and updating the information requires international cooperation, including the agreement of common policies for ownership and use of the data. Beneficiaries of such efforts will be not only the countries that assemble the databases from foreign museums, but the international scientific community as well, due to the increased scientific value that large databases coupled with modern computer technologies provide.
\end{abstract}

Surveying the biological diversity of a nation involves the inventorying, cataloging, and mapping of ecosystems, species, populations, and genes. It may also include research on the dynamic aspects of population biology, community and ecosystems ecology, and human uses of the different components of biodiversity. The task of biological surveying is among the oldest that biologists have faced (Badiano, 1552; Hernández, 1790). However, the increasing rate of ecosystem destruction with its associated species extinction and genetic erosion (McNeely et al., 1990; Wilson, 1992; Ehrlich, 1995; Whitmore \& Sayer, 1992), and the realization that perhaps $90 \%$ of the species on the planet remain to be named, not to mention mapped or understood (May, 1990; Groombridge, 1992; Stork, 1988), have added urgency to the problem. To address this urgency, new methods of documenting biodiversity are currently being developed-such as Rapid Assessment Programs (RAPs) (Conservation International, 1991, 1992, 1993a-c), the division of labor and information management methods of Costa Rica's Instituto Nacional de Biodiversidad (INBio) (Janzen et al., 1993), All Taxa Biotic Inventories (Janzen, 1993), new sampling methods including the so-called BioRaps (Margules \& Austin, 1995), where extrapolations of distributions are obtained prior to the sampling
(Margules \& Redhead, 1995), and advanced methods using sensors and pattern recognition software.

The reasons different societies and cultures may have for cataloging biodiversity run the spectrum from the strictly utilitarian to the philosophical and religious (Norton, 1987; Wilson, 1992). In countries like Mexico, which has a large, diverse rural population (Sarukhán et al., 1996), utilitarian reasons are very important. Indeed, in Mexico more than 3000 species are used as medicinal plants (Argueta et al., 1994), many other species have industrial applications (Sarukhán \& Dirzo, 1992), such as jojoba for high-grade oil, and there are hundreds of varieties of corn, beans, chile, and other species that are used for food. Still, non-utilitarian reasons for preserving biological diversity are expressed very forcefully by different segments of the public, such as outcries for protecting the monarch butterfly [Secretaría de Desarrollo Social (SEDESOL), 1993], waterfowl [Commission for Environmental Cooperation (CEC), 1995], marine mammals (Salinas \& Ladrón de Guevara, 1993), and other conspicuous species. A good example in plants is the recently discovered Lacandonia schismatica (Martínez \& Ramos, 1989), which despite being apparently useless and inconspicuous has been protected by the Chole Indian community of San Javier, Chiapas, at the cost of not clearing the remaining patch-

\footnotetext{
' We thank Peter Raven and the organizers of the Symposium for the invitation to participate. Many ideas presented here have been discussed extensively with Alejandro Pelaez, whose involvement we gratefully acknowledge. We also thank Mary Carmen Navarro and Rafael Caballero for the GIS work and species accumulation curves analyses, and Lupita Bermejo for helping with the references. Exequiel Ezcurra developed the algorithms for spatial analysis of collecting points. We are grateful to Amy Scheuler McPherson for very detailed and kind editorial work.

${ }^{2}$ Comisión Nacional Para el Conocimiento y Uso de la Biodiversidad (CONABIO) Fernández Leal 43, Coyoacán, México D.F. 04020, Mexico.

${ }^{3}$ Centro de Ecología, UNAM. Apdo. Postal 70-275, México 04510, Mexico.

${ }^{4}$ Museo de Zoología “Alfonso L. Herrera,” Fac. Ciencias, UNAM. Apdo. Postal 70-399, México D.F. 04510, Mexico.
}

AnN. Missouri Bot. Gard. 83: 562-573. 1996. 


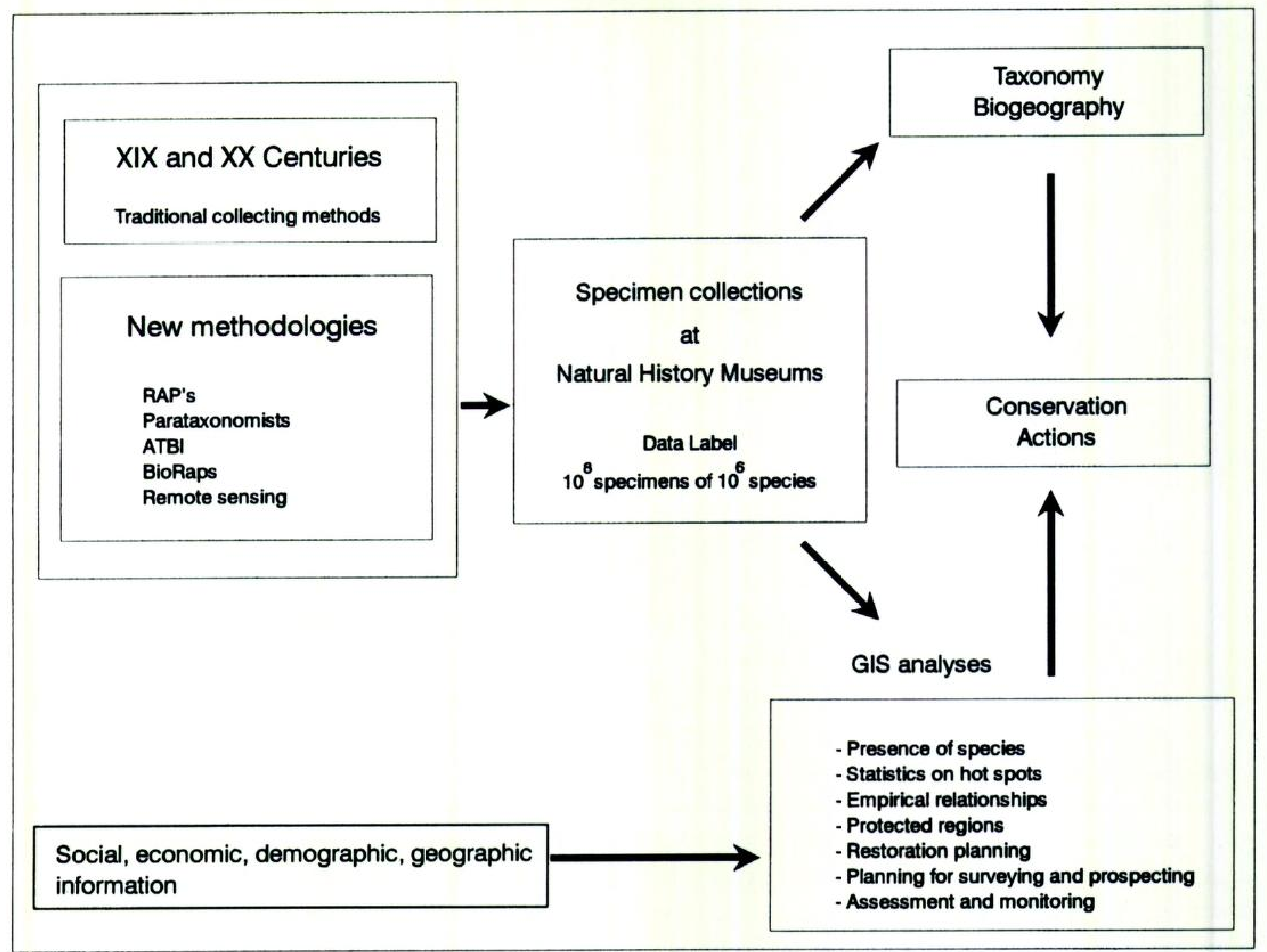

Figure 1. Traditional and new methods of collecting provide information about presence of species, mostly as labels on specimens. This information may ultimately have practical applications for conservation, alone or coupled with other types of data.

es of rainforest where the first population was discovered (Coello et al., 1993).

There is no doubt, then, that both in developed and underdeveloped countries different segments of the public, for different reasons, desire to preserve or sustainably use biodiversity. Consequently, governments have begun to design national programs for surveying biological diversity [National Research Council (NRC), 1993; Maddox \& Gee, 1994; Gámez et al., 1993; Environmental Resources Information Network (ERIN), http://www.erin.gov. au/general/], and to create multinational agencies or agreements that support or encourage such efforts (e.g., Global Environment Facility, Convention of Biological Diversity).

In this paper we will concentrate on surveying species from the point of view of the Mexican biodiversity agency, the Comisión Nacional de Biodiversidad (CONABIO). First, we will present arguments for inventorying existing collections and exploring the possible uses of the specimen label data. Second, we will describe our experiences and points of view on the role that foreign institutions play in such efforts. Third and finally, we will illustrate these two points using specific examples from CONABIO databases.

\section{The Usefulness of Label Data}

During the last two centuries major efforts were made to explore, collect, and inventory the natural world. Museums and collections are the depositories of the results, and it is because of the existence of the specimens located in those depositories that organized biological studies are possible (Janzen, 1993; Wheeler, 1995).

The museums and herbaria of the world hold in the order of $10^{8}$ specimens of an order of magnitude of about $10^{6}$ species (Chalmers, 1996), collected in localities that, to a certain gross spatial scale, cover most of the surface of the planet and an important part of its waters. Therefore, the information these specimens provide should represent the base for national inventories. However, for most of these specimens, we know little more than the date, location, collector, and name, and much of this in- 


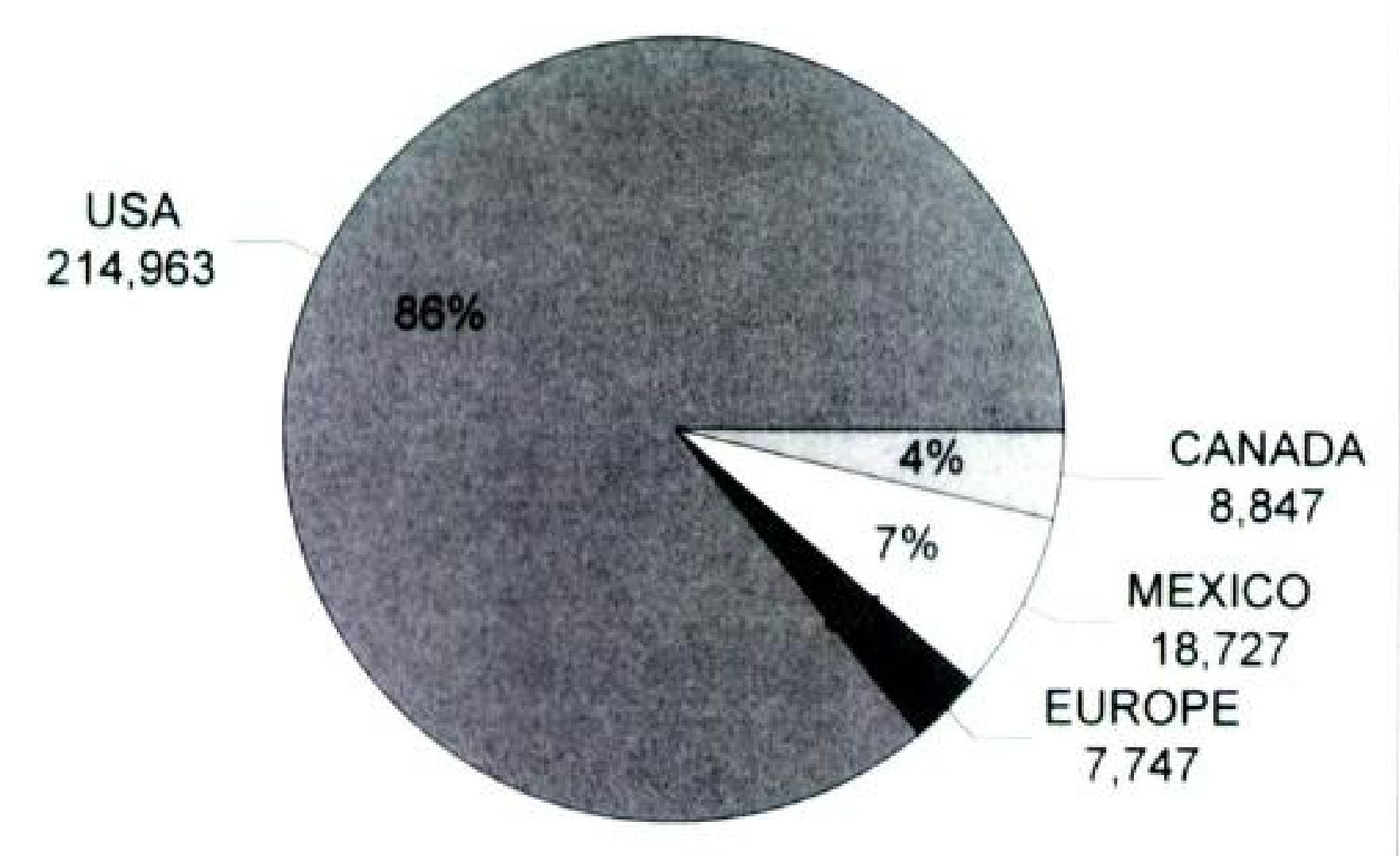

Figure 2. Graphic representation of the Bird Atlas of Mexico database showing the proportions of Mexican specimens that are housed in collections in different countries.

formation has some degree of uncertainty, both taxonomic and geographic. One obvious question is what use such apparently meager data has for conservation biology. Despite the serious limitations, such data have constituted the basis for much of classical biogeography, and it is the common ground where systematics, biogeography, and ecology come together to contribute to conservation biology (Fig. 1).

From the viewpoint of conservation biology, the basic results that label data from museums produce are lists of taxa and the distribution areas of taxa. Both types of biogeographical information are essential to the practical applications of conservation policies. In many countries, choosing areas to be preserved or finding locations of certain important species are the most common "scientific" tasks for conservationists (not to mention the economic, social, and political actions that in the end are the sine qua non of conservation).

In countries with high alpha and beta diversities but with a lack of knowledge about that diversity, having reliable lists and ways of extrapolating data from a collection locality to a larger area allow, among other things, the following:

(1) For a given site, determination of the likely presence of endemic, protected, scientifically interesting or economically important species (Bojórquez et al., 1995).

(2) Obtaining important statistics such as number of species and percentage of endemics. This also allows the location and mapping of hot and cold spots for better ecological planning (Prendergast et al., 1993; International Council for Bird Preservation, 1992; Nelson et al., 1990).

(3) Development of empirical relations between

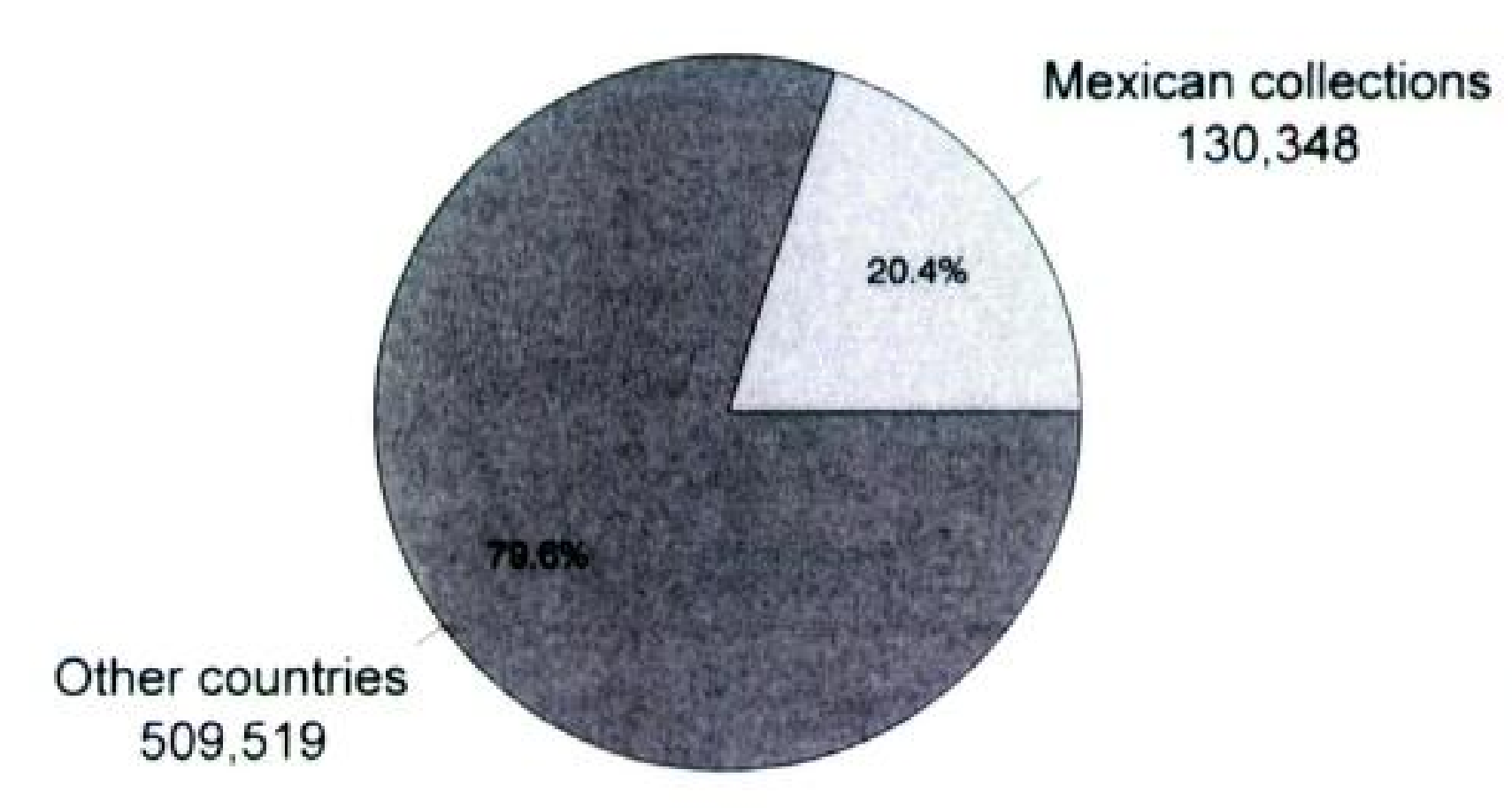

Figure 3. Graphic representation of CONABIO's allspecies databases showing the proportions of Mexican specimens housed in collections in different countries.

the above and easily measured climatic, geologic, and biological parameters to allow extrapolation (Margules \& Austin, 1995; Margules \& Redhead, 1995; Butterfield et al., 1994).

(4) Restoration planning using historical records or empirical rules for hypothetical distribution areas (Allen \& Wilson, 1991).

(5) Efficient planning of surveying and prospecting, both for areas lacking previous fieldwork using "hypothetical species lists" and for species of scientific or economic interest (Margules \& Redhead, 1995; Sittenfeld \& Gámez, 1993).

(6) Assessment and monitoring of global climate effects on the areas of species distributions (Chapman \& Busby, 1994).

Despite their usefulness, floristic and faunistic studies, and the development of procedures for the production of reliable distributional areas, have been the subject of far less theoretical and methodological development than other approaches such as, e.g., the population biological methods that underlie Minimum Viable Population Analysis (Soulé, 1987), and which are, at least in many underdeveloped countries, often far removed from the actual practice of conservation. There is no doubt, however, that the proper use of the huge amount of existing label information, in conjunction with modern computer systems, introduces many methodological and even theoretical issues, some of which we will discuss below, and therefore this should be an area of active research.

Of course, any information coming from museums, even assuming it is taxonomically adequate, may require field corroboration and is not a substitute for detailed ecological studies. But label information, because of the sheer abundance of it, its 


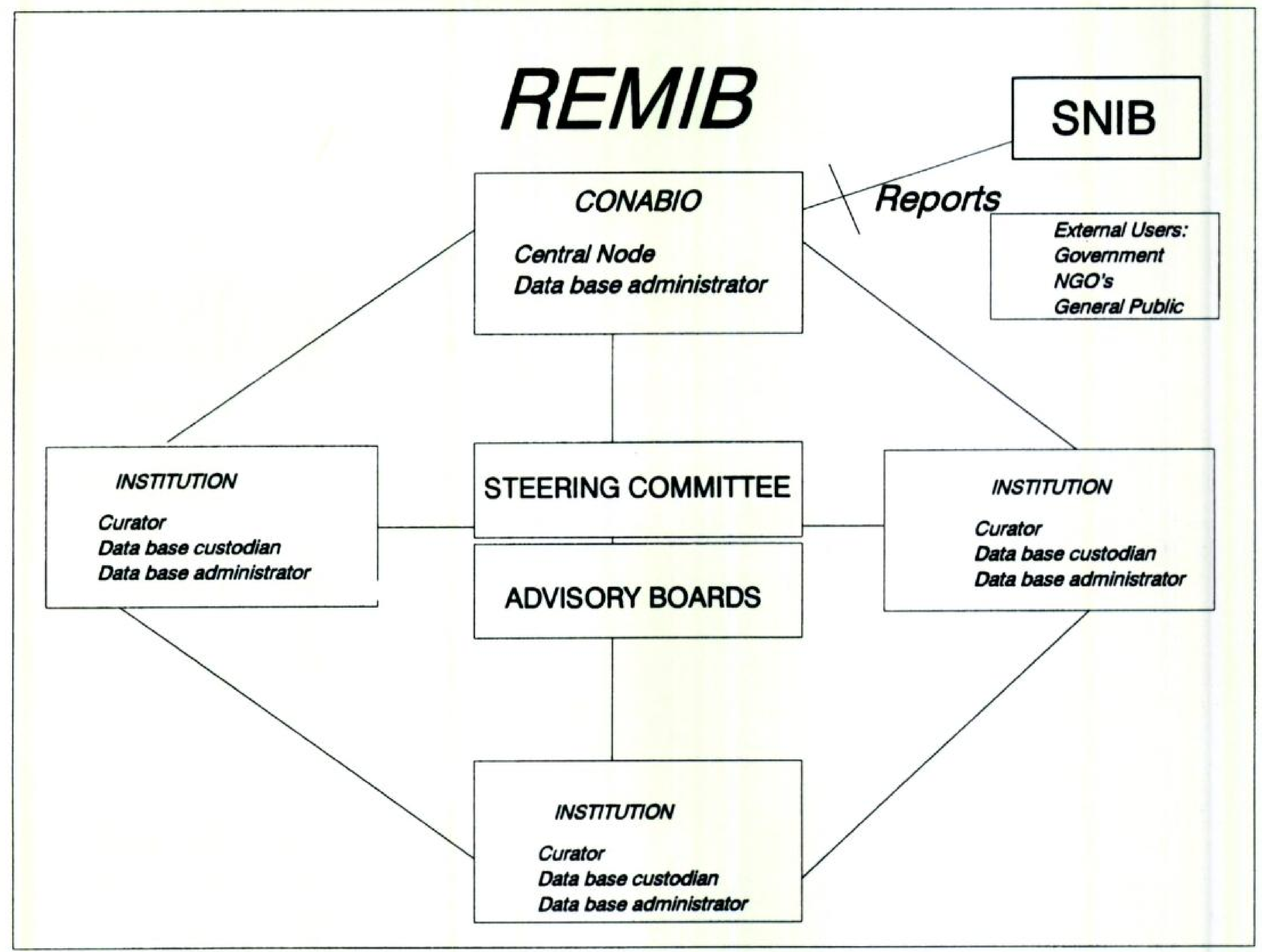

Figure 4. Structure of the Mexican network of biodiversity information (REMIB). The steering committee and advisory boards are academic bodies in charge of overseeing standards and membership to the network. SNIB is the national system of biodiversity information. The function of REMIB is to provide a mechanism for updating information maintained in the different institutions.

historical importance, and its direct relevance to important conservation questions, should have high priority in any national biological survey.

\section{Surveying the Museums of the World}

In this section we will rely heavily on the experiences of CONABIO that we believe are most amenable to generalization. Although CONABIO has supported a certain number of field studies, mainly on protected areas, and a pilot parataxonomist program, modeled on the experience of INBio, has been started, most of the efforts have been directed toward computerization of national collections and sharing information with foreign collections.

When CONABIO was created, its main objective was to promote the inventorying of Mexican biodiversity in computer data banks that could be updated regularly. There are several problems in fulfilling this task: (1) Clearly, to inventory all species inhabiting the Mexican territory is a task for generations. Priorities must be set. (2) Most of the specimens that have been collected in Mexico, with the exception of plants, are not held in Mexican collections. Sharing of data is necessary. (3) Gathering and updating the data are tasks for professional (or, in some cases, advanced amateur) taxonomists working in museums and herbaria. Policies and methods for determining the quality of data, acceptance and rejection criteria, accessing and updating the information, ownership, copyrights, economic compensation, etc., should be agreed upon between taxonomists and their institutions. (4) The size and distribution of the data make its capture in electronic formats expensive and time-consuming, requiring long-term commitments. (5) Given the dynamic and complex nature of taxonomic information and the lack of accepted standards for a taxonomic "data model," the creation of a suitable computer system was not trivial. (6) In order to be useful to a heterogeneous public-including government officers, scientists, members of non-governmental organizations (NGOs), and perhaps the general public-statistical, analyti- 


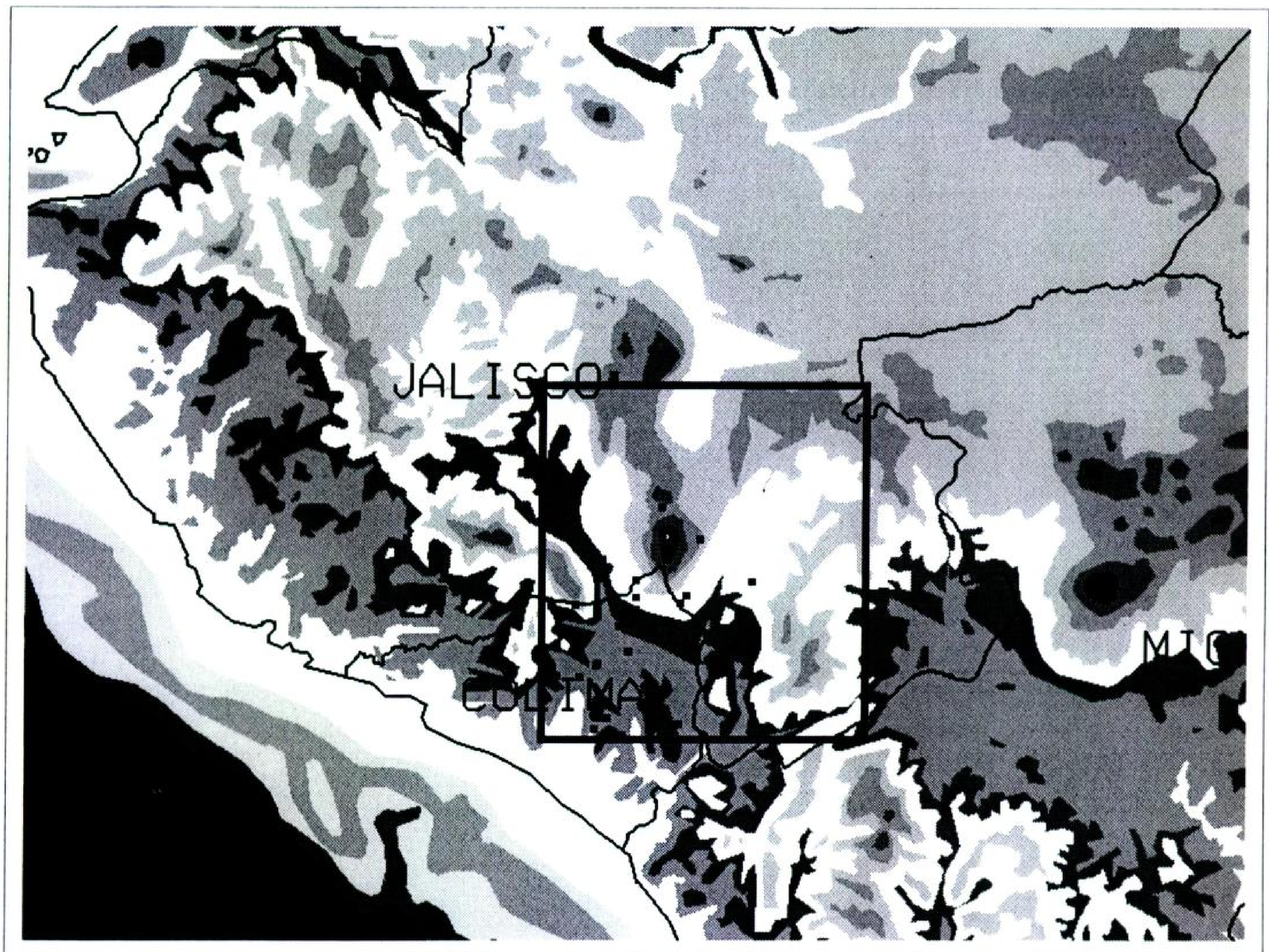

Figure 5. Distribution of collecting localities of two families of butterflies (Papilionidae and Pieridae) in a one degree per side square of the Pacific Coast of Mexico. The dots represent collection sites, and the shadings categories of altitude over sea level. Most collecting has been restricted to a limited range of altitude, suggesting that the sampling of ecological conditions is insufficient. The database used is the Butterflies Database of the Zoology Museum, School of Sciences, National University of Mexico.

cal, and display tools that help to organize the data in user-friendly and interesting ways should be devised and implemented.

\section{SETTING PRIORITIES}

Setting taxonomic and geographic priorities for the biological inventories was intensely discussed by CONABIO and its advisors. The final, pragmatic option we chose was to support work on groups in which Mexican experts were willing to work, or where there were ample and easily available data. In a second stage, results of these discussions will be used to pinpoint areas of both taxonomic and geographic ignorance. This leads many of the grants from CONABIO to be oriented toward vertebrates (terrestrial and aquatic), butterflies, some beetle families, and other important invertebrate groups, like certain families of parasitoid wasps and mollusks and annelids. The first results of those projects are now being used to plan field trips to fill in gaps, as will be described below.

\section{SHARING INFORMATION WITH FOREIGN INSTITUTIONS}

It is well known that many countries with great biological diversity do not house the best collections of their own flora and fauna. For example, about $90 \%$ of the bird specimens collected in Mexico are housed in foreign museums, mostly in the United States, Canada, and the United Kingdom (see Fig. 2). This is the case for almost any group considered at higher taxonomic categories, with the exception of vascular plants, for which there are two very large Mexican collections and several medium-sized ones. CONABIO is supporting the work of Mexican taxonomists to obtain information from the labels of specimens housed in foreign collections. In fact, by September 1995 almost $80 \%$ of CONABIO's data bank came from specimens housed in foreign collections (Fig. 3). To obtain the information a variety of procedures are used, from requesting computerized catalogs from curators to manually recording the information attached to each specimen. In this way, in the last two years 


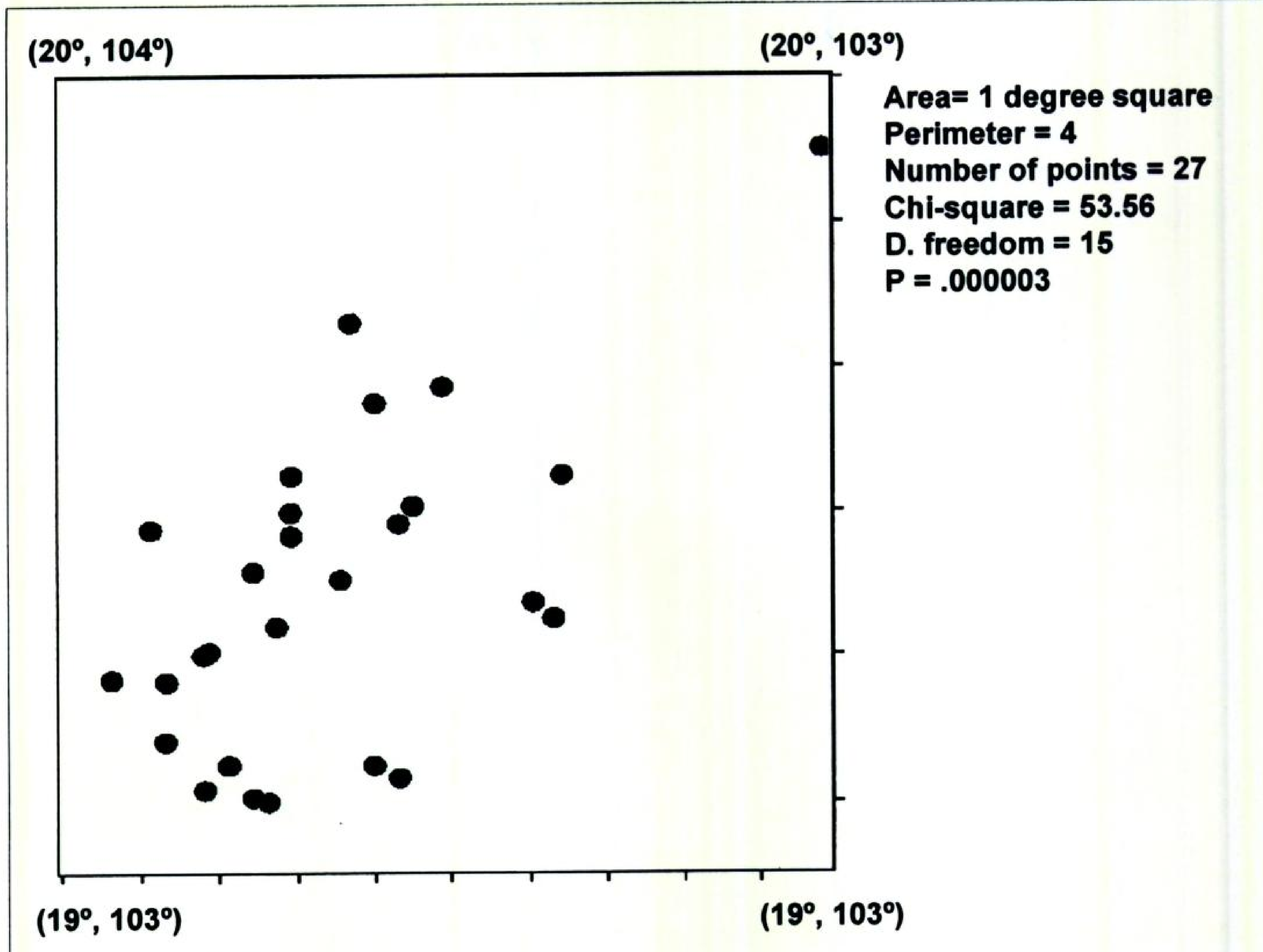

Figure 6. Spatial analyses of the data from Figure 5. Spatial distribution was analyzed for randomness of pattern, using standard techniques (see text). The null hypothesis of a random distribution of localities within the square was rejected.

information on hundreds of thousands of specimens, mostly of vertebrates and butterflies, have been assembled in databases now kept in some Mexican institutions, and eventually most of the information will be available through the Internet, via CONABIO's home-page.

Several interesting points can be learned from CONABIO's experience. When the work is done by taxonomists acquainted with the proper handling of collections, almost all foreign museums have been open to and helpful with the effort of computerizing labels. Among other things, this sometimes benefits the museums that lack computerized catalogs or the resources to computerize large collections. However, there were a number of concerns related to the idea as a whole. Most concerns of providers are associated with the precise conditions for releasing information to the public domain. In many cases this issue has been resolved by carefully stating the rights of the providers following ideas already used by the Australian Environmental Resources Information Network (ERIN), or contained in the published Association for Scientific Collections' (ASC,
1993) "Guidelines for Institutional Database Policies." These points can be formalized by signing letters of agreement or Memoranda of Understanding between the national biodiversity agency and the foreign museum. In our case, CONABIO has already signed a Memorandum of Understanding with the British Museum of Natural History, and is working on other such agreements.

\section{POLICIES ABOUT OWNERSHIP AND UPDATING}

Ownership of information is a subject closely related to the above. Although who is the "owner" of information in a public museum is open to discussion, there is no doubt that the museums, the curators of the collections, and the taxonomic experts are the actors directly involved in creating and updating the information, and they should be the authorities on the use of it. CONABIO is following the experience of ERIN regarding the concept of custodianship of the information. This means that we agree that only the providers of the databases and the curators of the collections have the authority to 


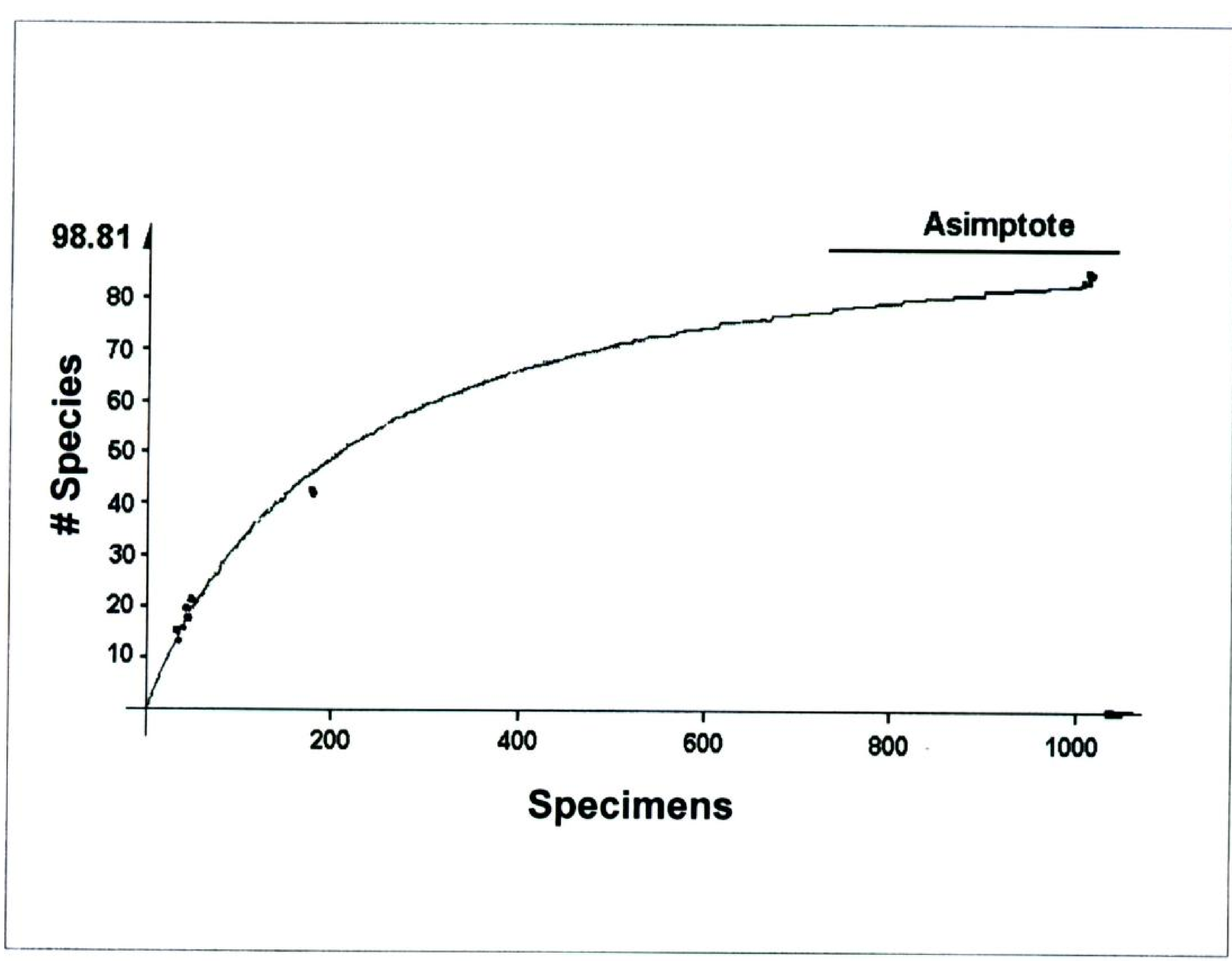

Figure 7. Species-effort analyses of the data from Figure 6. Using CONABIO's database, an accumulation of number of new species plotted as a function of collecting effort (number of specimens in five-year intervals) was done. The curve shows that for the area sampled there is a decreasing rate of new registers, and the asymptote of the curve (about 99 species) is near the last value of different species (86) collected in the area. See text for further explanation.

modify the databases. It also means that if part of the information is regarded as sensitive (for example, precise georeferencing of populations of commercially valuable endangered species) or not yet ready to use by non-experts (for example, if it is not stable taxonomically), the providers or curators have the authority to mark the fields or records as access-restricted.

CONABIO, as well as some other national biodiversity agencies (INBio, ERIN), supports a policy of open access to most of the basic information on biodiversity, that is, the label data. However, this is not universally agreed upon, and therefore before releasing any information to the public domain the formal agreements and permits should state at least what parts of the information are considered open, the disclaimers and pointers in the databases that identify the original sources and dates of the information, the responsibility (or lack thereof) of the sources, the procedures to report to the sources the amount of use of their information, and any updating mechanisms for the database.
The periodic updating of databases containing label data from many tens of thousands of specimens located in dozens of institutions in many countries is not a simple task. However, the existence of the Internet makes the task feasible. Pioneering efforts are already under way by many institutions that are making their catalogs available on-line through the World Wide Web. Among the many entry points, Cornell University Biodiversity and Biological Collections is a useful one. (Its URL is: http://muse.bio.cornell.edu.) Nevertheless, a truly distributed database of museum information is still lacking. A major international effort will be required to reach this goal (Systematics Agenda 2000, 1994).

In Mexico, CONABIO is coordinating a network of institutions in an effort called Red Mexicana de Información sobre Biodiversidad (REMIB), in which the partner institutions will have access to the information held in each collection using widely available Internet navigators. Although short of full interoperability of the databases, this will allow the 


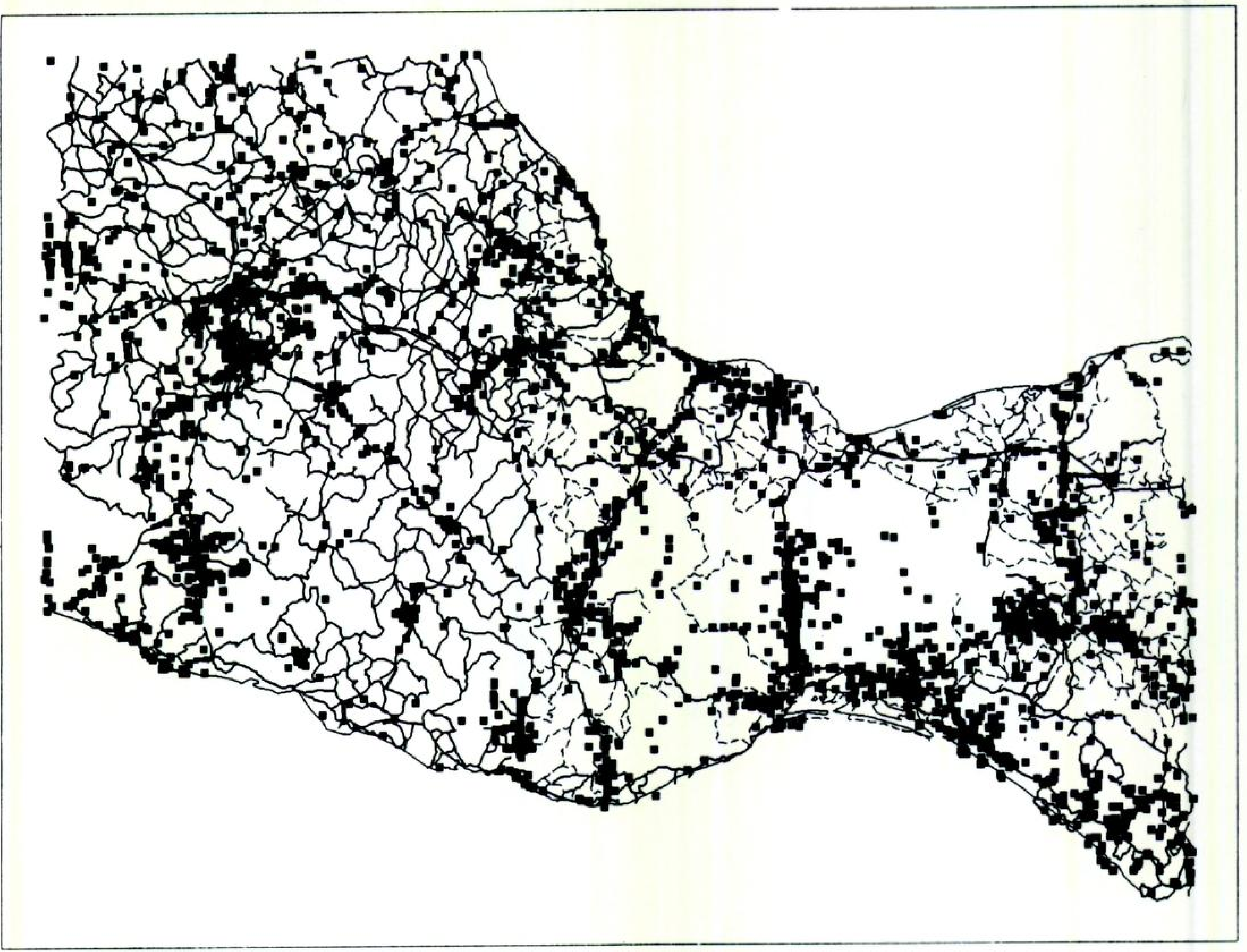

Figure 8. Dots represent collecting points in the Bird Atlas of Mexico database, near the Isthmus of Tehuantepec, in southern Mexico. Lines are roads. The figure displays the "Collector's Syndrome," in which dots tend to accumulate along roads or around biological stations.

partners to retrieve information on-line and to gain experience with the problems of creating a distributed database (Fig. 4).

\section{LONG-TERM COMMITMENTS}

Any country that attempts to create national inventories must be prepared to make a long-term commitment. Not only are lists incomplete even for vertebrates, but the detailed georeferencing required for modern studies (Margules \& Redhead, $1995)$ is available only for certain groups or in a few countries. In the developing world, this will require the creation and strengthening of national capacities in terms of physical and human infrastructure (at the technical, professional, and research levels) to do conventional exploring and taxonomic work, but since most of the already existing data are based in museums in the developed countries, some new commitments are required. As an example, we can take the Birds of Mexico database that was compiled by A. Navarro and H. Benítez of the Museo Alfonso L. Herrera, at the School of Sci- ences of the National University of Mexico, and Townsend Peterson, of Kansas University. This database took more than five years and visits to 40 museums in seven countries to be assembled. The georeferencing of the locations has been going on for three years, and the debugging of the geographical fields alone has involved some 30,000 of the total 280,000 records. Maintaining and updating this database will be a permanent task that may require a budget to allow for trained personnel, traveling, computer resources, etc. Because scientific grants are difficult to obtain for these efforts, governments may have to allocate money specifically for the compilation and maintenance of these databases. All the other databases of a national scope that CONABIO is supporting (mammals, fishes, reptiles and amphibians, butterflies, and scarabeid beetles) have taken many years to be compiled and georeferenced and will require continuous efforts by their custodians at universities to maintain, debug, and update. This effort will cost resources and institutional commitments at national and international levels. 


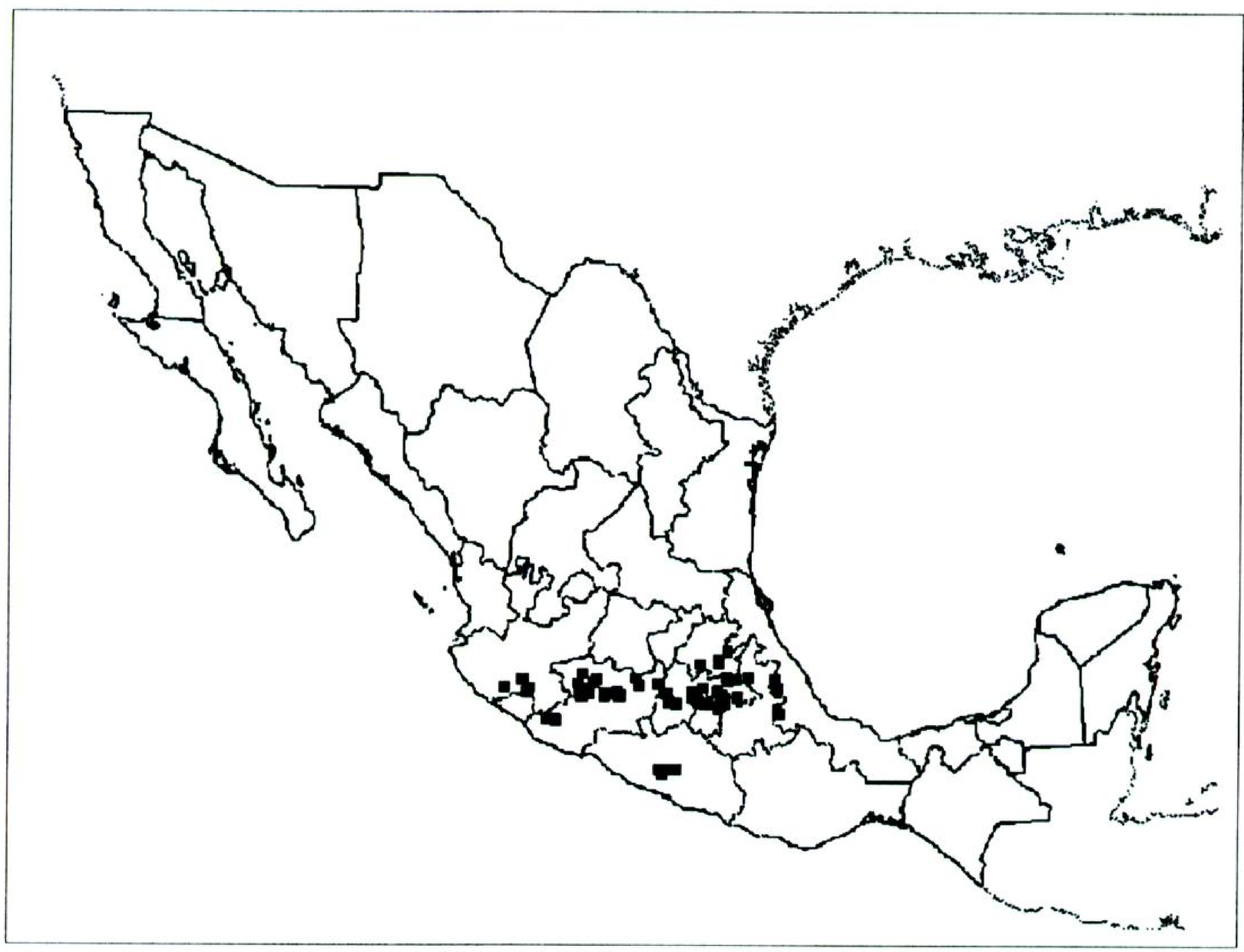

Figure 9. Collecting localities for Abies religiosa. Data are from herbarium specimens deposited at the Instituto Nacional de Investigaciones Agropecuarias y Forestales (INIFAP).

The commitment also means participating in the many international forums that deal with this subject. Since the issue of sharing and updating collections information on a global scale has presented a great many questions, it is important that many opinions and points of view be taken into account when agreeing on policies, standards, methods, etc. Currently, there are several more or less international efforts addressing these problems, groups like the International Organization for Plant Information (IOPI), the Working Group on Taxonomic Databases (TDWG), the International Union for Biological Sciences' group DIVERSITAS, and initiatives like Systematics Agenda 2000, Species 2000, and the Clearing House of the Biological Diversity Convention. Regular participation from member countries is needed in order to maintain an institutional memory.

\section{DESIGN OF A DATA MODEL}

To date, there is no single agreed-upon data model that can be used for an effective exchange of information among data holders around the world. This is an important subject to confront if we are to exchange and update information from different sources efficiently and consistently.

Several data models are in use in institutions around the world, for example, the databases MUSE (http://muse.bio.cornell.edu/), SMASCH (http://ucjeps.berkeley.edu/smasch.html), and TROPICOS (http://www.mobot.org/MOBOT/research/datamodel.html) and others accessible through the Biodiversity and Biological Collections Home page (http://muse.bio.cornell.edu/). However, this effort is not complete, and becomes even more complicated when other themes are added to the purely taxonomic information. CON$\mathrm{ABIO}$ has dedicated significant time, money, and human resources to define a data model that can adequately address the diverse needs of government institutions dealing with the manifold aspects associated with biological information.

In many cases incompatible data formats among museums highlight the additional standardization effort that is required to be able to use information 


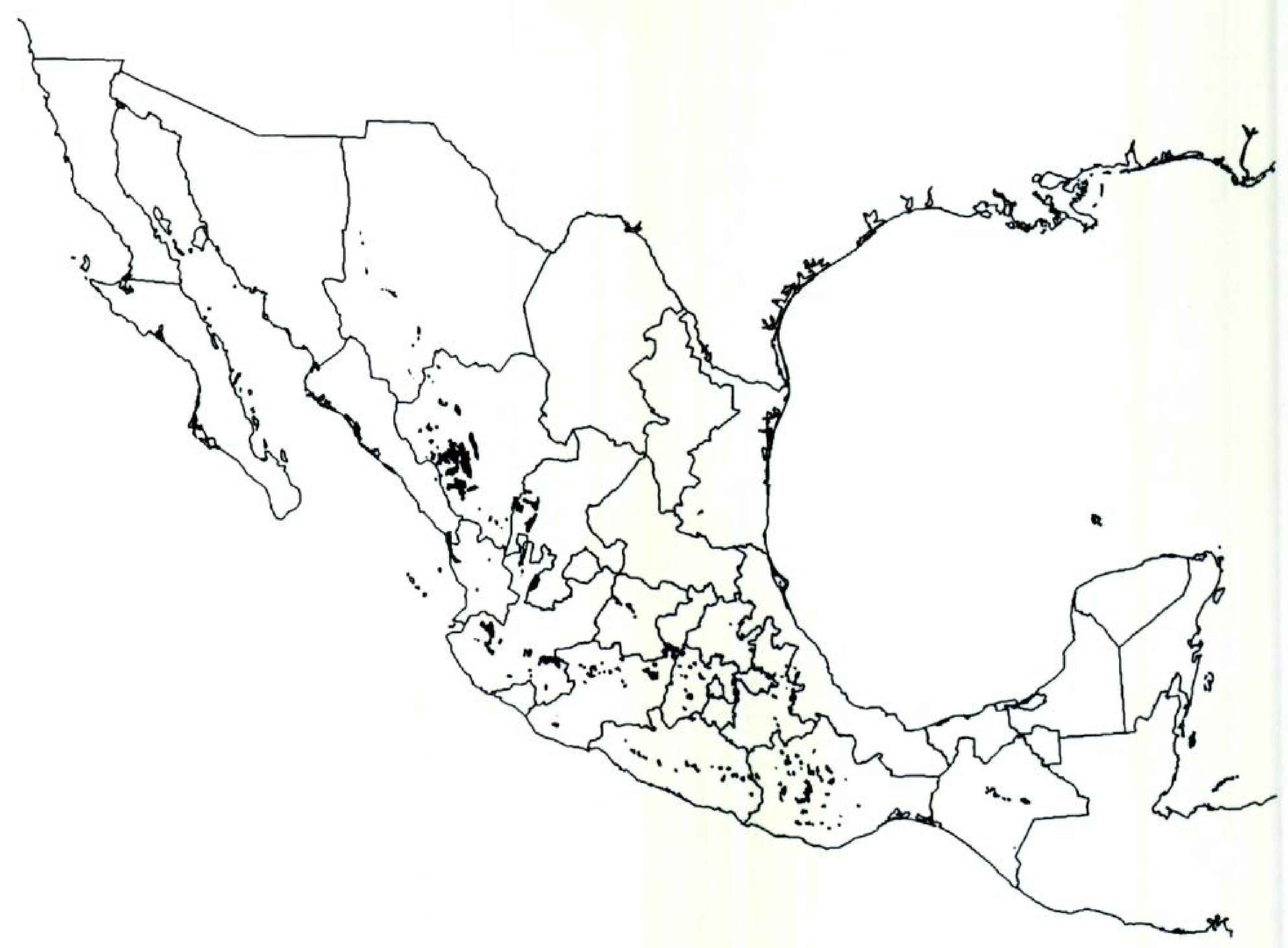

Figure 10. Data on altitude, precipitation, and average yearly temperature were obtained for the collecting localities in the previous figure. The geographical information system was then used to plot other localities with similar conditions (see text).

from different sources. Taxonomists and scientific societies throughout the world must participate more actively in order to propose and enforce more effective "standards" for taxonomic information, since curatorial information represents the "core" of any biodiversity information system.

\section{ANALYTICAL TOOLS}

Amassing large databases of label information requires the development of many tools for its analysis. This includes, first, display and exploratory tools. Since the information and its interpretation are basically geographical, Geographical Information Systems (GIS) are an essential tool for displaying and organizing the data. However, due to large gaps of knowledge, inferential and predictive tools are also needed. Given the non-randomness of these samples (in space, time, and taxa), and the fact that most label information is just presence data, this presents some interesting statistical problems.

As an example of display tools, in Figure 5 we present the distribution of collecting localities of
Papilionid and Pierid butterflies (the database comes from 15 museums in Mexico, the United States, Canada, and Europe) in a one degree per side square on the Pacific Coast of Mexico. At a glance one can tell that most of the highlands are not well sampled. An analysis of the randomness of the spatial distribution (Pielou, 1969) confirms that the points are far from being randomly distributed (Fig. 6). In Figure 7 an accumulation curve (Soberón \& Llorente, 1993) is displayed. This curve shows that the effort concentrated on the area covered by the points has resulted in a significant drop in the discovery of new species. The two exploratory tools show that although the lowlands in the square may be adequately sampled, more effort is required in sampling other areas.

In another example, in Figure 8 we show the collecting localities for birds in Mexico. The map clearly displays the artifactual pattern created by overcollecting along roads or near biological stations and points out gaps where few or no collecting efforts have been made. This type of information is already being used by CONABIO to evaluate the 
information about location of species provided in some environmental impact assessments.

On the matter of predictive methods, empirical modeling of the presence data as a function of easily measured, climatic or physiographic variables holds great promise (Butterfield et al., 1994). In Figure 9 we display the points where the fir Abies religiosa has been collected, according to the data of the Instituto Nacional de Investigaciones Forestales, Agrícolas y Pecuarias (INIFAP) herbarium in Mexico. In Figure 10 the shaded areas show regions where similar conditions of average temperature, precipitation, and elevation occur. Similar regions were defined using a boxcar method (Carpenter et al., 1993). It is quite possible that the large shaded areas may include non-reported localities for Abies religiosa, and perhaps for other species of Abies as well. Inclusion of the information of other national and foreign herbaria would lead to a much better analysis. Leaving aside the work of Soto and Gomez-Pompa (1990), empirical modeling is just beginning in Mexico, and although the Australian experience shows that the tool has predictive power, more work is needed in the mountainous regions of Mexico. The possibilities that empirical modeling opens for bioprospecting, planning, and restoration are significant. The National Reforestation Program in Mexico will be using this tool for planning their actions in the immediate future.

\section{Conclusions}

The use of label information that is currently housed in the many museums around the world will be extremely useful for ecological planning and monitoring. The ability to assemble large label databases, together with the computing tools required to analyze them, is increasing the value of collections, museums, and the work of taxonomists around the world. Besides the practical implications for prospecting for important species, restoration and reforestation, ecological planning, locating priority areas, and monitoring and evaluating environmental impact statements, the scientific applications of the databases are quite interesting. Biogeographical and ecogeographical analyses previously done on the scales of thousands of square kilometers may be refined a thousandfold. Empirical modeling should conduce to forming hypotheses and suggesting mechanisms for explaining the correlations found.

For most countries all the above requires more than just national efforts. The collaboration of museums all over the world, together with scientific societies and many multilateral agencies and pro- grams, will be needed to computerize and distribute the information, agree on policies and standards, develop methods and techniques for analyses, and provide funds.

\section{Literature Cited}

Allen, R. B. \& J. B. Wilson. 1991. A method for determining indigenous vegetation from simple environmental factors, and its use for vegetation restoration. Biol. Conservation 56: 265-280.

Argueta, A., L. M. Cano \& M. E. Rodarte. 1994. Atlas de las Plantas de la Medicina Tradicional Mexicana. Three volumes. Instituto Nacional Indigenista, México D.F.

Association for Scientific Collections (ASC). 1993. ASC guidelines for institutional database policies. ASC Newsletter 21(6): 61-75.

Badiano, J. 1552. Libellus de Medicinalibus Indorum Herbis. In M. de la Cruz. 1991. Aztec manuscript from 1552 , according to Latin introduction by Juan Badiano (Spanish version with studies and comments from several authors). 2 volumes. Fondo de Cultura Económica e Instituto Mexicano del Seguro Social, Mexico D.F.

Bojórquez, L., I. Azuara, E. Ezcurra \& O. Flores. 1995. Identifying conservation priorities in Mexico, through GIS and modeling. Ecol. Applications 5: 215-231.

Butterfield, B. R., B. Csuti \& J. M. Scott. 1994. Modeling vertebrate distributions for gap analysis. Pp. 53-68 in Ronald Miller (editor), Mapping the Diversity of Nature. Chapman \& Hall, London.

Carpenter, G., A. N. Gillison \& J. Winter. 1993. DOMAIN: A flexible modeling procedure for mapping potential distributions of plants and animals. Biodiversity and Conservation 2: 667-680.

Chalmers, N. 1996. Monitoring and inventorying biodiversity: Collections, data and training. Pp. 171-179 in F. Di Castro \& T. Younes, Biodiversity, Science and Development: Towards a New Partnership. CAB International, Wallingford, United Kingdom.

Chapman, A. D. \& J. R. Busby. 1994. Linking plant species information to continental biodiversity inventory, climate modeling and environmental monitoring. Pp. 179-194 in Ronald Miller (editor), Mapping the Diversity of Nature. Chapman \& Hall, London.

Coello, G., A. Escalante \& J. Soberón. 1993. Lack of genetic variation in Lacandonia schismatica (Lacandoniaceae: Triuridales) in its only known locality. Ann. Missouri Bot. Gard. 80: 898-901.

Commission for Environmental Cooperation (CEC). 1995. Secretariat Report on the Death of Migratory Birds at the Silva Reservoir (1994-95). Commission for Environmental Cooperation, Montreal.

Conservation International (CI). 1991. A Biological Assessment of the Alto Madidi Region and Adjacent Areas of Northwest Bolivia. Conservation International, Washington, D.C.

1992. Status of Forest Remnants in the Cordillera de la Costa and Adjacent Areas of Southwestern Ecuador. Conservation International, Washington, D.C.

. 1993a. A Biological Assessment of the Columbia River Forest Reserve, Toledo District, Belize. Conservation International, Washington, D.C.

1993b. The Lowland Dry Forests of Santa Cruz,

Bolivia: A Global Conservation Priority. Conservation 
International, Fundación Amigos de la Naturaleza, Washington, D.C.

1993c. A Biological Assessment of the Kanuku Mountain Region of Southwestern Guyana. Conservation International, Washington, D.C.

Ehrlich, R. P. 1995. The scale of the human enterprise and biodiversity loss. Pp. 214-226 in J. Lawton \& R. M. May (editors), Extinction Rates. Oxford Univ. Press, Oxford.

Gámez, R., A. Piva, A. Sittenfeld, E. León, J. Jiménez \& G. Mirabelli. 1993. Costa Rica's conservation program and the National Biodiversity Institute (INBio). Pp. 5368 in W. Reid, A. Sittenfeld, S. Laird, D. Janzen, C. Meyer, M. Gollin, R. Gamez \& C. Juma (editors), Biodiversity Prospecting: Using Genetic Resources for Sustainable Development. World Resources Institute, Washington, D.C.

Groombridge, B. 1992. Global Biodiversity Status of the Earth's Living Resources. World Conservation Monitoring Centre. Chapman \& Hall, London

Hernández, F. 1790. Historia Plantarum Novæ Hispaniæ. In: Historia Natural de Nueva España. 1960. Volumes I-III. Facsimile Edition. Universidad Nacional Autónoma de México. México D.F.

International Council for Bird Preservation (ICBP). 1992. Putting Biodiversity on the Map: Priority Areas for Global Conservation. International Council for Bird Preservation, Cambridge, United Kingdom.

Janzen, D. H. 1993. Taxonomy: Universal and essential infrastructure for development and management of tropical wildland biodiversity. Pp. 100-113 in 0. Terje \& P. J. Schei (editors), Proceedings of the Norway/UNEP Expert Conference on Biodiversity. Directorate for Nature Management, Trondheim, Norway.

, W. Hallwachs, R. Gámez, A. Sittenfeld \& J. Jiménez. 1993. Research management policies: Permits for collecting and research in the tropics. Pp. 131-157 in W. Reid, A. Sittenfeld, S. Laird, D. Janzen, C. Meyer, M. Gollin, R. Gamez \& C. Juma (editors), Biodiversity Prospecting: Using Genetic Resources for Sustainable Development. World Resources Institute, Washington, D.C.

Maddox, J. \& H. Gee. 1994. Mexico's bid to join the World. Nature 368: 789-804.

Margules, C. R. \& M. P. Austin. 1995. Biological models for monitoring species decline: The construction and use of databases. Pp. 183-196 in J. Lawton \& R. M. May (editors), Extinction Rates. Oxford Univ. Press, Oxford.

— \& T. D. Redhead. 1995. BioRap. Guidelines for Using the BioRap Methodology and Tools. CSIRO, Dickson, Australia.

Martínez, E. \& C. H. Ramos. 1989. Lacandoniaceae (Triuridales): Una nueva familia de México. Ann. Missouri Bot. Gard. 76: 128-135.

May R. M. 1990. How many species? Philos. Trans. Roy. Soc. London, B330: 292-304.

McNeely, J. A., K. R. Miller, W. V. Reid, R. Mittermeier \& T. Werner. 1990. Conserving the World's Biological Diversity. International Union for the Conservation of
Nature and the World Resources Institute. Gland, Switzerland.

National Research Council (NRC). 1993. A Biological Survey for the Nation. National Academy Press, Washington, D.C.

Nelson, B. W., C. A. C. Ferreire, M. F. da Silvan \& M. L. Kawasaki. 1990. Endemism centres, refugia and botanical collection density in Brazilian Amazonia. Nature 345: 714-716.

Norton, B. G. 1987. Why Preserve Natural Variety? Princeton Univ. Press, Princeton, New Jersey.

Pielou, E. C. 1969. An Introduction to Mathematical Ecology. John Wiley \& Sons, New York.

Prendergast, J. R., R. M. Quinn, J. L. Lawton, B. C. Eversham \& D. W. Gibbons. 1993. Rare species, the coincidence of diversity hotspots and conservation strategies. Nature 365: 335-337.

Salinas, M. \& P. Ladrón de Guevara. 1993. Riqueza y diversidad de los mamíferos marinos. Ciencias, Facultad de Ciencias, Universidad Nacional Autónoma de México. Special Number 7.

Sarukhán, J. \& R. Dirzo. 1992. México ante los retos de la biodiversidad. Comisión Nacional para el Conocimiento y Uso de la Biodiversidad, México D.F.

- J. Soberón \& J. Larson. 1996. Biological conservation in a high Beta-diversity country. Pp. 171-179 in F. di Castri \& T. Younes, Biodiversity, Science and Development: Towards a New Partnership. CAB International, Wallingford, United Kingdom.

Secretaría de Desarrollo Social (SEDESOL). 1993. Reunión sobre la mortandad de la mariposa monarca en México. Avándaro, México.

Sittenfeld, A. \& R. Gámez. 1993. Biodiversity prospecting by INBio. Pp. 69-67 in W. Reid, A. Sittenfeld, S. Laird, D. Janzen, C. Meyer, M. Gollin, R. Gamez \& C. Juma (editors), Biodiversity Prospecting: Using Genetic Resources for Sustainable Development. World Resources Institute, Washington, D.C.

Soberón, J. \& J. B. Llorente. 1993. The use of species accumulation functions for the prediction of species richness, Conservation Biol. 7: 480-488.

Soto, M. \& A. Gómez-Pompa. 1990. Bioclimatología de la Flora de Veracruz. No. 1. Instituto de Ecología A.C., Xalapa, México.

Soulé, M. (Editor). 1987. Viable Populations for Conservation. Cambridge Univ. Press, Cambridge.

Stork, N. E. 1988. Insect diversity: Fact, fiction and speculation. Biol. J. Linn. Soc. 35: 321-337.

Systematics Agenda 2000 (SA2000). 1994. Systematics Agenda 2000: Charting the Biosphere. Technical Report by the Association of Systematics Collections, New York.

Wheeler, Q. D. 1995. Systematics, the scientific basis for inventories of biodiversity. Biodiversity and Conservation 4: 476-489.

Whitmore, T. C. \& J. A. Sayer. 1992. Tropical Deforestation and Species Extinction. Chapman \& Hall, London.

Wilson, E. O. 1992. The Diversity of Life. The Belknap Press of Harvard Univ. Press, Cambridge, Massachusetts. 


\title{
The following text is generated from uncorrected OCR.
}

\section{[Begin Page: Page 562]}

\author{
AN INTERNATIONAL VIEW \\ OF NATIONAL BIOLOGICAL \\ SURVEYS'

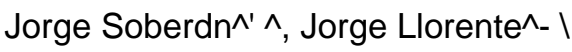 \\ and Hesiquio Bendez^ *
}

Abstract

Museums and herbaria in industrialized countries hold a huge amount of data in the form of labels associated with specimens collected in developing countries. These data represent a significant part of the existing information on biodiversity available for most developing countries. In this paper we first discuss the usefulness of the label information,

providing some examples from Mexico. Acquiring and updating the information requires international cooperation, including the agreement of common policies for ownership and use of the data. Beneficiaries of such efforts will be not

only the countries that assemble the databases from foreign museums, but the international scientific community as

well, due to the increased scientific value that large databases coupled with modern computer technologies provide.

Surveying the biological diversity of a nation in- (Margules \& Redhead, 1995), and advanced meth-

volves the inventorying, cataloging, and mapping of ods using sensors and pattern recognition software,

ecosystems, species, populations, and genes. It may The reasons different societies and cultures may

also include research on the dynamic aspects of have for cataloging biodiversity run the spectrum 
population biology, community and ecosystems from the strictly utilitarian to the philosophical and

ecology, anil human

of the different compo- religious (Norton, 1987; Wilson, 1992). In countries

nents of biodiversity. The task of biological survey- like Mexico, which has a large, diverse rural poping is among the oldest that biologists have faced ulation (Sarukhan et al., 1996), utilitarian reasons

(Badiano, 1552; llemdndez, 1790). However, the are very important. Indeed, in Mexico more than

increasing rate of ecosystem destruction with its as- 3000 species are used as medicinal plants (Argueta

sociated species extinction and genetic erosion et ah, 1994), many other species have industrial

(McNeely et al., 1990; Wilson, 1992; Ehrlich, applications (Sarukhan \& Dirzo, 1992), such as jo-

1995; Whitmore \& Sayer, 1992), and the realization joba for high-grade oil, and there are hundreds of

that perhaps $90 \%$ of the species on the planet re- varieties of corn, beans, chile, and other species

to be

$d$, not to mention mapped or un- that

used for food. Still, non-utilitarian reasons 
derstood (May, 1990; Groombridge, 1992; Stork, for preserving biological diversity are expressed 1988), have added urgency to the problem. To ad- very forcefully by different segments of the public, dress this urgency, new methods of documenting such as outcries for protecting the monarch butterbiodiversity are currently being developed — such fly [Secretaria de Desarrollo Social (SEDESOL), as Rapid Assessment Programs (RAPs) (Conserva- 1993], waterfowl [Commission for Environmental tion International, 1991, 1992, 1993a-c), the di- Cooperation (CEC), 1995], marine mammals (Salivision of labor and information management meth- nas \& Ladrdn de Guevara, 1993), and other conods of Costa Rica's Instituto Nacional de spicuous species. A good example in plants Is the Biodiversidad (INBio) (Janzen et al., 1993), All recently discovered Lacandonia schismatica (MarTaxa Biotic Inventories (Janzen, 1993), new sam- tinez \& Ramos, 1989), which despite being apparpling methods including the so-called BioRaps ently useless and inconspicuous has been protected (Margules \& Austin, 1995), where extrapolations of by the Chole Indian community of San Javier, Chiadistributions are obtained prior to the sampling pas, at the cost of not clearing the remaining patch-

' We thank Peter Haven and the organizers of the Symposium for the invitation to parlieipate. Many ideas presented here have been diseussed extensively with Alejandro Pelaez, whose involvement we gratefully acknowledge. We also

thank Mary Carmen Navarro and Rafael Caballero for the GIS work and species accumulation curves analyses, and

Lupita Bermejo for helping with the references. Exequiel Ezcurra developed the algorithms for spatial analysis of collecting [)oints. We are grateful to Amy Scheuler McPherson for very detailed and kind editorial work.

^ Comisi6n Nacional Para el Conocimiento y Uso de la Biodiversidad (CONABIO) Fernandez Leal 43, Coyoacdn, Mexico D.E 04020, Mexico.

' Centro de Ecologfa, UNAM. Apdo. Postal 70-275, Mexico 04510, Mexico.

* Museo de Zoologfa "Alfonso L. Herrera," Fac. Ciencias, UNAM. Apdo. Postal 70-399, Mexico D.F. 04510, Mexico. 
Ann. Missouri Bot. Card. 83: 562-573. 1996.

\section{[Begin Page: Page 563]}

Volume 83, Number 4

1996

Soberon et al.

International View

563

XIX and XX Centuries

Traditional collecting methods

New methodologies

RAP'S

Parataxonomists

ATBI

BioRaps

Remote sensing

Taxonomy 


\section{BJogeography}

Specimen collections

at

Natural History Museums

Data Label

66

10 specimens of 10

Conservation

Actions

GIS analyses

Social, economic, demographic, geographic information

- Presence of species

- Statistics on hot spots

- Empirical relationships 
- Protected regions

- Restoration planning

- Planning for surveykig and prospecting

- Assessment and monitoring

Figure 1. Traditional and new methods of collecting provide information about presence of species, mostly as labels

on specimens. This information may ultimately have practical applications for conservation, alone or coupled with other

types of data.

es of rainforest where the first population was dis- play in such efforts. Third and finally, we will il-

covered (Coello et al., 1993).

lustrate these two points using specific examples

There is no doubt, then, that both in developed from CONABIO databases, and underdeveloped countries different segments of

the public, for different reasons, desire to preserve $\mathrm{j}^{\wedge \wedge}$ USEFULNESS OF Label Data or sustainably use biodiversity. Consequently, gov-

ernments have begun to design national programs

During the last two centuries major efforts were 
for surveying biological diversity [National Re- made to explore, collect, and inventory the natural search Council (NRC), 1993; Maddox \& Gee, 1994; world. Museums and collections are the deposito-

Gdmez et al., 1993; Environmental Resources In- riesofthe

Its, and it is because of the existence

formation Network (ERIN), http://www.erin.gov. of the specimens located in those depositories that

$\mathrm{au} / g e n e r a l /]$, and to create multinational agencies organized biological studies are possible (Janzen,

or agreements that support or encourage such ef- 1993; Wheeler, 1995).

forts (e.g., Global Environment Facility, Convention Tlie museums and herbaria of the world hold in

of Biological Diversity). the order of $10^{\star *}$ specimens of an order of magnitude

In this paper we will concentrate on surveying of about KY' species (Chalmers, 1996), collected in

species from the point of view of the Mexican bio- localities that, to a certain gross spatial scale, cover

diversity agency, the Comision Nacional de Biodi- most of the surface of the planet and an important

versidad (CONABIO). First, we will present argu- part of its waters. Therefore, the information these

ments for inventorying existing collections and specimens provide should represent the base for

exploring the possible uses of the specimen label national inventories. However, for most of these 
data. Second, we will describe our experiences and specimens, we know little more than the date, lo-

points of view on the role that foreign institutions cation, collector, and name, and much of this in-

\section{[Begin Page: Page 564]}

564

Annals of the

Missouri Botanical Garden

USA

214,963

1

CANADA

8,847

MEXICO

18.727

\section{EUROPE}

$1.7 \mathrm{~A} 1$

Figure 2. Gra|)hic representation of the Bird Atlas of 
Mexico database showing the proportions of Mexican

specimens that arc housed in collections in different coun-

tries.

$20.4 \%$

$\backslash$ -

$70.6 \%$

Other countri

509,519

Mexican collections

130.348

l

Figure 3. Graphic representation of CONABIOs all-

species databases showing the proportions of Mexican

specimens housed in collections in different countries.

formation has sonu' degree of uncertainty, both tax- the above and easily measured climatic, geologic,

onomic and geograpliic. One obvious question is and biological parameters to allow extrapolation

what use such apparently meager data has for con- (Margules \& Austin, 1995; Margules \& Redhead, 
servation biology. Despite the serious limitations, 1995; Butterfield et al., 1994).

such data have constituted the basis for much of (4) Restoration planning using historical records

classical biogeography, and it is the common or empirical rules for hypothetical distribution ar-

ground where systcmatics, biogeography, and ecol- eas (Allen \& Wilson, 1991).

ogy come together to contribute to conservation bi-

ology (Fig. 1).

(5) Efficient planning of surveying and prospect-

ing, both for areas lacking previous fieldwork using

From the viewpoint of conservation biology, the "hypothetical species lists" and for species of scibasic results that label data from museums produce entific or economic interest (Margules \& Redhead, are lists of taxa and the distribution

Both types of biogt^ographical information are es-

s of taxa. 1995; Sittenfeld \& Gdmez, 1993).

(6) Assessment and monitoring of global climate

sential to the practical applications of conservation effects on the areas of species distributions (Chappolicies. In many countries, choosing areas to be man \& Busby, 1994).

preserved or finding locations of certain important 
Despite their usefulness, floristic and faunistic

species are the most common "scientific" tasks for studies, and the development of procedures for the conservationists (not to mention the economic, so- production of reliable distributional areas, have cial, and political actions that in the end are the been the subject of far less theoretical and meth-

sine qua non of conserl'ation).

odological development than other approaches such

In countries with high alpha and beta diversities as, e.g., the population biological methods that un-

but with a lack of knowledge about that diversity, derlie Minimum Viable Population Analysis (Soul<^,

having reliable lists and ways of extrapolating data 1987), and which are, at least in many underde-

from a collection locality to a larger area allow, veloped countries, often far removed from the ac-

among other things, the following:

tual practice of conservation. There is no doubt,

(1) For a given site, determination of the likely however, that the proper use of the huge amount of presence of endemic, protected, scientifically inter- existing label information, in conjunction with modesting or economically important species (Bojor- ern computer systems, introduces many methodquez et al., 1995). ological and even theoretical issues, some of which

(2) Obtaining important statistics such as number we will discuss below, and therefore this should be of species and percentage of endemics. This also an area of active research. 
allows the location and mapping of hot and cold

Of course, any information coming from muse-

spots for better ecological planning (Prendergast et urns, even assuming it is taxonomically adequate, al., 1993; International Council for Bird Preserva- may require field conoboration and is not a sub-

tion, 1992; Nelson et al., 1990).

stitute for detailed ecological studies. But label in-

(3) Development of empirical relations between formation, because of the sheer abundance of it, its

\section{[Begin Page: Page 565]}

Volume 83, Number 4

1996

Sober6n et al.

Intemational View

565

REMIB

SNIB 
CONABIO

Central Node

Data base administrator

iNSTITUnON

Curator

Data tjase custodian

Data t)ase administrator

Externai Users:

Government

NGO's

General Pubiic

STEERING COMMITTEE

ADVISORY BOARDS

INSTITUnON 
Curator

Data $t>$ ase custodian

Data t>ase administrator

INSTITUTION

Curator

Data base custodian

Data t>ase administrator

Figure 4. Structure of the Mexican network of biodiversity information (REMIB). The steering committee and advisory boards are academic bodies in charge of overseeing standards and membership to the network. SNIB is the

national system of biodiversity information. The function of REMIB is to provide a mechanism for updating information

maintained in the different institutions.

historical importance, and its direct relevance to specimens that have been collected in Mexico, with important conservation questions, should have high the exception of plants, are not held in Mexican

priority in any national biological survey.

Surveying the Museums of the World

In this section we will rely heavily on the ex-

periences of CONABIO that we believe are most 
amenable to generalization. Although CONABIO

collections. Sharing of data is necessary. (3) Gath-

ering and updating the data are tasks for profes-

sional (or, in some cases, advanced amateur) tax-

onomists working in museums and herbaria.

Policies and methods for determining the quality of

data, acceptance and rejection criteria, accessing

has supported a certain number of field studies, ${ }^{\wedge " \wedge} " P^{* \wedge \wedge} \wedge^{\prime \prime} g$ ' ${ }^{\wedge \wedge}$ information, ownership, copy-

mainly on protected areas, and a pilot parataxono- "S^ts, economic compensation, etc., should be

mist program, modeled on the experience of INBio, ${ }^{\wedge} \mathrm{g}^{\wedge \star \wedge} \ll^{\wedge} \wedge$ "P $\ll$ " between taxonomists and their instihas been started, most of the efforts have been di- $t " \wedge i 0 " «-W$ The size and distribution of the data rected toward computerization of national collec- make its capture in electronic formats expensive tions and sharing information with foreign collec- and time-consuming, requiring long-term commitments. (5) Given the dynamic and complex nature

tions.

When CONABIO was created, its main objective of taxonomic information and the lack of accepted was to promote the inventorying of Mexican biodi- standards for a taxonomic "data model," the creaversity in computer data banks that could be up- tion of a suitable computer system was not trivial, dated regularly. There are several problems in ful- (6) In order to be useful to a heterogeneous pubfilling this task: (1) Clearly, to inventory all species lie - including government officers, scientists, inhabiting the Mexican territory is a task for gen- members of non-governmental organizations (NGOs), erations. Priorities must be set. (2) Most of the and perhaps the general public - statistical, analyti- 


\section{[Begin Page: Page 566]}

566

Annals of the

Missouri Botanical Garden

Figure 5. Dislrilxilion of collecting localities of two families of butterflies (Papilionidae ami Pieridae) in a one degree per side stjuare of the Pacific Coast of Mexico. The dots represent collection sites, and the shadings categories

of altitude over sea level. Most collecting has been restricted to a limited range of altitude, suggesting that the sampling

of ecological conditions is insufficient. The database used is the Butterflies Database of the Zoology Museum, School

of Sciences, National University of Mexico.

cal, and display tools that help to organize tlie data SHARINC; INFORMATION WITH FORKIGN INSTITUTIONS

in user-friendly and interesting ways should $\mathrm{l}>\mathrm{e}$ de-

1

vised anc

$1 \mathrm{impl}$

erne

$\mathrm{nl}\left({ }^{\wedge} \mathrm{d}\right.$. 
It is well known that many countries with great

biological diversity do not house the best collec-

tions of their own flora and fauna. For example,

about $90 \%$ of the bird specimens collected in Mex-

Setting taxonomic and geographic priorities for ico are housed in foreign museums, mostly in the

\section{SETTING PRIORITIRS}

the biological inventories was intensely discussed United States, Canada, and the United Kingdom by CONABIO and its advisors. Th( ${ }^{*}$ final, pragmatic (see Fig. 2). This is the case for almost any group

option we chose was to support work on groups in considered at higher taxonomic categories, with the which Mexican experts were willing to work, or exception of vascular plants, for which there ;

where there were ample and easily available data. two very large Mexican collections and several meIn a second stage, results of these discussions will dium-sized ones. CONABIO is supporting the work

be used to pinpoint areas of both taxonomic and of Mexican taxonomists to obtain information from

geographic ignorance. This leads many of the the labels of specimens housed in foreign collecgrants from CONABIO to be oriented toward ver- tions. In fact, by September 1995 almost $80 \%$ of tebrates (terrestrial and aquatic), butterflies, some CONABIO's data bank came from specimens

beetle families, and other important invertebrate housed in foreign collections (Fig. 3). To obtain the groups, like certain families of parasitoid wasps and infonnation a variety of procedures are used, from

mollusks and annelids. The first results of those requesting computerized catalogs from curators to 
projects are now being used to plan field trips to manually recording the information attached to

fill in gaps, as will be described below.

each specimen. In this way, in the last two years

[Begin Page: Page 567]

Volume 83, Number 4

1996

Soberon et al.

International View

567

(20», $104 ")$

$\left(20^{\circ}, 10 Z^{\prime \prime}\right)$

$\mathrm{T}$

T

$\mathrm{T}$ 
Area $=1$ degree square

Perimeter $=4$

Number of points $=27$

Chi-square $=53.56$

D. freedom $=15$

$\mathrm{P}=.000003$

$\left(19^{\wedge} 103^{\circ}\right)$

$\left(19^{\circ}, 103^{\circ}\right)$

Figure 6.

using standard techniques (

rejected.

Spatial analyses of the data from Figure 5. Spatial distribution was analyzed for randomness of pattern,

ee text). The null hypothesis of a random distribution of localities within the square was

99

ormalized by sign

information on hundreds of thousands of speci- 1993) "Guidelines for Institutional Database Poli- 
mens, mostly of vertebrates and butterflies, have cies.

been assembled in databases now kept in some letters of agreement or Memoranda of Understand-

Mexican institutions, and eventually most of the in- ing between the national biodiversity agency and

format

CONABIO's home-page.

the foreign museum. In our case, CONABIO has

gned a Memorandum of Understanding

Several interesting points can be learned from with the British Museum of Natural History, and is CONABIO's experience. When the work is done by working on other such agreements, taxonomists acquainted with the proper handling of

collections, almost all foreign museums have been policies ABOUT OWNERSHIP AND UPDATING open to and helpful with the effort of computerizing labels. Among other things, this sometimes benefits

ormation

the museums that lack computerized catalogs or the lated to the above. Although who is the "owner" of resources to computerize large collections. How- information in a public museum is open to discus- 
ever, there were a number of concerns related to sion, there is no doubt that the museums, the cu-

the idea as a whole. Most concerns of providers are rators of the collections, and the taxonomic experts associated with the precise conditions for releasing are the actors directly involved in creating and up-

nform

nformati

this issue has been resolved by carefully stating the thorities on the use of it. CONABIO is following the

rights of the providers following ideas already used experience of ERIN regarding the concept of cus-

by the Australian Environmental Resources Infor- todianship of the information. This means that we

mation Network (ERIN), or contained in the pub- agree that only the providers of the databases and

Hshed Association for Scientific Collections' (ASC, the curators of the collections have the authority to

\section{[Begin Page: Page 568]}

568

Annals of the

Missouri Botanical Garden 
Figure 7. Species-effort analyses of the data from Figure 6. Using CONABIO's database, an accumulation of number

of new species pb)tte(l as a function of collecting effort (number of specimens in five-year intervals) was done. The cune shows that for the area sampled there is a decreasing rate of new registers, and the asymptote of the curve (about

99 species) is near the last value of differenl species (86) collected in the area. See text for further explanation.

modify the databases. It also means that if part of The periodic updating of databases containing

the information is regarded as sensitive (for exam- label data from many tens of thousands of speci-

ple, precise georeferencing of populations of com- mens located in dozens of institutions in many

mercially valuable endangered species) or not yet countries is not a simple task. However, the exis-

ready to use by non-experts (for example, if it is tence of the Internet makes the task feasible. Pio-

not stable taxonomically), the providers or curators neering efforts are already under way by many in-

have the authority to mark the fields or records as stitutions that are making their catalogs available

on-line through the World Wide Web. Among the

access-restricte $<1$.

CONABIO,

well 
as some other national bio- many entry points, Cornell University Biodiversity

diversity agentues (INBio, ERIN), supports a policy and Biological Collections is a useful one. (Its URL

of open access to most of the basic information on is: http://muse.bio.coniell.edu.) Nevertheless, a tru-

biodiversity, that is, the label data. However, this ly distributed database of museum

ly distributed database of museum information is

is not universally agreed upon, and therefore before still lacking. A major international effort will be

releasing any infonnation to the public domain the required to reach this goal (Systematics Agenda

formal agreements and permits should state at least 2000, 1994).

what parts of the information are considered open. In Mexico, CONABIO is coordinating a network

the disclaimers and pointers in the databases that of institutions in an effort called Red Mexicana de

identify the original sources and dates of the infor- Informacidn sobre Biodiversidad (REMIB), in

mation, the responsibility (or lack thereof) of the which the partner institutions will have access to

sources, the procedures to report to the sources the the information held in each collection using widely

amount of use of their information, and any updat- available Internet navigators. Although short of full 
ing mechanisms for die database. interoperability of the databases, this will allow the

\section{[Begin Page: Page 569]}

Volume 83, Number 4

1996

Sober6n et al.

Intemational View

569

Figure 8. Dols represent collecting points in the Bird Atlas of Mexico database, near the Isthmus of Tehuantepec, in southern Mexico. Lines are roads. The figure displays the "Collector's Syndrome," in which dots tend to accumulate

along roads or around biological stations.

\section{LONG-TERM COMMITMENTS}

partners to retrieve information on-line and to gain ences of the National University of Mexico, and

experience with the problems of creating a distrib- Townsend Peterson, of Kansas University, This da-

uted database (Fig. 4). tabase took more than five years and visits to 40

museums in seven countries to be assembled. The

georeferencing of the locations has been going on

for three years, and the debugging of the geograph-

Any country that attempts to create national in- $\mathrm{j}^{\wedge}$ al fields alone has Involved some 30,000 of the 
ventories must be prepared to make a long-term total 280,000 records. Maintaining and updating commitment. Not only are lists incomplete even for $t^{\wedge} j g$ database will be a permanent task that may vertebrates, but the detailed georeferencing re- require a budget to allow for trained personnel, quired for modem studies (Margules \& Redhead, traveling, computer resources, etc. Because scien1995 ) is available only for certain groups or in a tific grants are difficult to obtain for these efforts, few countries. In the developing world, this will governments may have to allocate money specifirequire the creation and strengthening of national cally for the compilation and maintenance of these capacities in terms of physical and human infra- databases. All the other databases of a national structure (at the technical, professional, and re- scope that CONABIO is supporting (mammals, fishsearch levels) to do conventional exploring and tax- es, reptiles onomic work, but since most of the already existing abeid beetles) have taken many years to be comdata are based in museums in the developed coun- piled and georeferenced and will require contries, some new commitments are required. As an tinuous efforts by their custodians at universities to example, we can take the Birds of Mexico database maintain, debug, and update. This effort will cost that was compiled by A. Navarro and $\mathrm{H}$. Benitez of resources and institutional commitments at national the Museo Alfonso L. Herrera, at the School of Sci- and intemational levels.

and

\section{[Begin Page: Page 570]}

570

Annals of the

Missouri Botanical Garden

$<\mathrm{y}^{\wedge} \wedge_{-} \wedge \wedge \mathrm{M} !$ 
Figure 9. Collecting localities for Abies religiosa. Data are from herbarium specimens deposited at the Instituto Nacional de Investigaciones Agropecuarias y Forestales (INIP'AP).

The commitment also means participating in the of information among data holders around the many international forums that deal with this sub- world. This is an important subject to confront if ject. Since the issue of sharing and updating col- we are to exchange and update information from lections information on a global scale has presented different sources efficiently and consistently. a great many questions, it is important that many Several data models are in use in institutions opinions and points of view be taken into account around the world, for example, the databases when agreeing on policies, standards, methods, etc. MUSE (http://muse.bio.cornell.edu/), SMASCH

C

urren

tly, th 
ere are

ral more or less interna- (http://ucjeps.berkeley.edu/smasch.html), and

tional efforts addressing these problems, groups TROPICOS (http://www.mobot.org/MOBOT/re-

like the International Organization for Plant Infor- search/datamodel.html) and others accessible

maticm (IOPI), the Working Group on Taxonomic through the Biodiversity and Biological Collec-

Databases (TDWG), the International Union for Bi- tions Home page (http://muse.bio.cornell.edu/).

ological Sciences' group DIVERSITAS, and initia- However, this effort is not complete, and becomes

tives like Systematics Agenda 2000, Species 2000, even more complicated when other themes are

and the Clearing House of the Biological Diversity added to the purely taxonomic information. CON-

Convention. Regular participation from member $\mathrm{ABIO}$ has dedicated significant time, money, and

countries is needed in order to maintain an insti- human resources to define a data model that can

tutional memory.

the diverse needs of govern-

adequately add 
ment institutions dealing with the manifold as-

DKSI(;n of a data MODFX $\mathrm{P}^{\wedge \wedge \wedge \wedge}$ associated with biological information.

In many cases Incompatible data fonnats among

To date, there is no single agreed-upon data museums highlight the additional standardization

model that can be used for an effective exchange effort that is required to be able to use information

\section{[Begin Page: Page 571]}

Volume 83, Number 4

1996

Soberon at al.

International View

571

9

Figure 10. Data on altitude, precipitation, and average yearly temperature were obtainetl for the collecting localities in the previous figure. The geographical information system was then used to plot other localities with similar conditions

(see text). 
from different sources. Taxonomists and scientific Papilionid and Pierid butterflies (the database throughout the world must participate comes from 15 museums in Mexico, the United

societies

more actively in order to propose and enforce more States, Canada, and Europe) in a one degree per effective "standards" for taxonomic information, side square on the Pacific Coast of Mexico. At a since curatorial information represents the "core" of any biodiversity information system.

glance one can tell that most of the highlands are not well sampled. An analysis of the randomness of the spatial distribution (Pielou, 1969) confirms that the points are far from being randomly distrib-

Amassing large databases of label information "t^^ (Fig. 6). In Figure 7 an accumulation curve requires the development of many tools for its anal- (Soberon \& Llorente, 1993) is displayed. This curve ysis. This includes, first, display and exploratory ${ }^{\wedge}$ ows that the effort concentrated on the area cov-

ANALYTICAL TOOI^

ormat

ered by the points has resulted in a significant drop rrrbasiclUy"geogra7hical7 Geographical Informs- in the discovery of new species. The two exploration Systems (GIS) are an essential tool for dis- tory tools show that although the lowlands in the playing and organizing the data. However, due to square may be adequately sampled, more effort is large gaps of knowledge, inferential and predictive required in sampling other areas. 
tools are also needed. Given the non-randomness In another example, in Figure 8 we show the of these samples (in space, time, and taxa), and the collecting localities for birds in Mexico. The map fact that most label information is just presence clearly displays the artifactual pattern created by data, this presents some interesting statistical prob- overcollecting along roads or near biological sta$\lg \wedge g$ tions and points out gaps where few or no collecting

As an example of display tools, in Figure 5 we efforts have been made. This type of information is present the distribution of collecting localities of already being used by CONABIO to evaluate the

\section{[Begin Page: Page 572]}

572

Annals of the

Missouri Botanical Garden

information a!)out location of species provided in grams, will be needed to computerize and distribute some environmental impact assessments.

the information, agree on policies and standards,

Literature Cited

On the matter of predictive methods, empirical develop methods and techniques for analyses, and modeling of the presence data as a function of eas- provide funds.

ily measured, climatic or physiographic variables

holds great promise (Butterfield et ah, 1994). In 
Figure 9 we display the points where the fir Abies

religiosa has been collected, acconUng to the data Allen, R. B. \& J. B. Wilson. 199L A method for Jeterof the Instituto Nacional de Investigaciones Fores- mining indigenous vegetation from simple environmen-

tal factors, and its use for vegetation restoration. Biol.

Conservation 56: 265-280.

Arguela, A., L M. Cano \& M. E. Rodarte. 1994. Atlas

de las Plantas de la Medicina Tradicional Mexicana.

Three volumes. Instituto Nacional Indigenista, Mexico

D.F.

Association for Scientific Collections (ASC). 1993. ASC

guidelines for institutional database policies. ASC

Newsletter 21(6): 61-75.

Badiano, J. 1552. Libellus de Medicinalibus Indorum

Herbis. In M. de la Cruz. 1991. Aztec manuscript from

1552, according to Latin introduction by Juan Badiano

(Spanish version with studies and comments from sev-

eral authors). 2 volumes. Fondo de Cultura Econ6mica

e Instituto Mexicano del Seguro Social, Mexico D.F.

ginning in Mexi(M), and although the Australian ex- Boj6rquez, L, I. Azuara, E. Ezcurra \& 0. Flores. 1995.

perience shows that the tool has predictive power. Identifying conservation priorities in Mexico, through 
tales, Agrfcolas y Pecuarias (INIFAP) herbarium in Mexico. In Figure 10 the shaded areas show regions where similar conditions of average temperature, precipitation, and elevation occur. Similar Regions were defined using a boxcar method (Carpenter et al., 1993). It is quite possible that the large shaded areas may include non-reported localities ior Abies religiosa, and perhaps for other species of Abies as well. Inclusion of the information of other national and foreign herbaria would lead to a much better analysis. Leaving aside the work of Soto and Go-Pompa (1990), empirical modeling is just be-

more work is needed in the mountainous regions of CIS and modeling. Ecol. Applications 5: 215-231.

M^vio^ TU^-krr a . ! 11 - Butterfield, B. R., B. Csuti \& J. M. Scott. 1994. Modeling

Mexico. The possibdities that empirical modeling vertebrH.e di^trihntinn. for .nn .n.lv.i= P. $\wedge_{-}^{\wedge \wedge}$;.

opens for bioprospecting, planning, and restoration

$-m_{-}{ }^{\wedge} \vee \mathrm{m}$

Ronald Miller (editor). Mapping the Diversity of Nature. 
are significant. The National Reforestation Program Chapman \& Hall, London

in Mexico will be using this tool for planning their Carpenter, G., A. N. Gillison \& J. Winter. 1993. DO-

actions in the immediate future.

Conclusions

The use of label information that is currently

housed in the many museums around the world will

MAIN: A flexible modeling procedure for mapping po-

tential distributions of plants and animals. Biodiversity

and Conservation 2: 667-680.

Chalmers, N. 1996. Monitoring and inventorying biodi-

versity; Collections, data and training. $\mathrm{Pp} .171-179$ in

F. Di Castro \& T. Younes, Biodiversity, Science and

Development: Towards a New Partnership. CAB Inter-

V 1 r 1 r 1.11. , national, Wallingford, United Kingdom.

be extremely useful for ecologieal planning and Chapman, A, D. \& J. R. Busby. 1994. Unking plant spenionitonng. The abdity to assemble large label da- cies information to continental biodiversity inventory,

tabases, together with the computing tools required climate modeling and environmental monitoring. Pp.

to analyze them, is increasing the value of collec-

tions, museums, and the work of taxonomists

around the world. Besides the practical implica- 
tions for prospecting for important species, resto-

ration and reforestation, ecological planning, locat-

ing priority areas, and monitoring and evaluating

environmental impact statements, the scientific ap-

plications of the databases are quite interesting.

Biogeographical and ecogeographical analyses pre- C

viously done on the scales of thousands of square

kilometers may be refined a thousandfold. Empiri-

cal modeling should conduce to forming hypotheses _

and suggesting mechanisms for explaining the cor- lera de la Costa and Adjacent AreaVof Southwe7t $7^{\wedge \wedge}$

179-194 in Ronald Miller (editor), Mapping the Diver-

sity of Nature. Chapman \& Hall, London.

Coello, C, A. Escalante \& J. Sober6n. 1993. Lack of

genetic variation in Lacandonia schismatica (Lacandon-

iaceae: Triuridales) in its only known locality Ann. Mis-

souri Bot. Card. 80: 898-901.

Conunission for Environmental Cooperation (CEC). 1995.

Secretariat Report on the Death of Migratory Birds at

the Silva Reservoir (1994-95). Commission for Envi-

ronmental Cooperation, Montreal.

Conservation International (Cl). 1991. A Biological As-

sessment of the Alto Madidi Region and Adjacent Areas 
of Northwest Bolivia. Conservation International, Wash-

ington, D.C.

1992. Status of Forest Remnants in the Cordil-

Ecuador. Conservation International, Washington, D.C.

1993a. A Biological Assessment of the Colum-

relations found.

For most countries all the above requires more

than just national efforts. The collaboration of inu- $\wedge^{\prime \prime \wedge}$ River Forest Reserve, Toledo District, Belize. Con-

$",,,,, \ldots, \ldots \wedge$ servation International, Washmcton, D.C.

seums all over the world, together with scientific . 1993b. The Lowland Drj Forests of Santa Cruz,

societies and many multilateral agencies and pro- Bolivia: A Global Conservation Priority. Conservation

\section{[Begin Page: Page 573]}

Volume 83, Number 4

1996

Soberon et al.

International View 
International, Fundaci6n Amigos cle la Naturaleza,

Washington, D.C

Nature and the World Resources Institute. Gland, Swit-

zerland.

1993c. A Biological Assessment of the Kanuku National Research Council (NRC). 1993. A Biological

Survey for the Nation. National Academy Press, Wash-

ington, D.C.

Nelson, B. W., C. A. C. Ferreire, M. F. da Silvan \& M. L.

Kawasaki. 1990. Endemism centres, refugia and bo-

tanical collection density in Brazilian Amazonia. Nature

345: 714^716.

Norton, B. G. 1987. Why Preserve Natural Variety?

Princeton Univ. Press, Princeton, New Jersey.

Pielou, E. C. 1969. An Introduction to Mathematical

Ecology, John Wiley \& Sons, New York.

Prendergast, J. R., R. M. Quinn, J. L. Lawton, B. C. Ev-

ersham \& D. W. Gibbons. 1993. Rare species, the co-

incidence of diversity hotspots and consenation strat- 
egies. Nature 365: 335-337.

Salinas, M. \& P. Ladr6n de Guevara. 1993. Riqueza y

diversidad de los mamfferos marinos. Ciencias, Facultad de Ciencias, Universidad Nacional Aut6noma de

Mexico. Special Number 7.

Sarukhdn, J. \& R. Dirzo. 1992. Mexico ante los retos de la biodiversidad. Comisidn Nacional para el Conocimienlo y Uso de la Biodiversidad, Mexico D.F. , J. Sober6n \& J. Larson. 1996. Biological conservation in a high Beta-diversity country. Pp. 171-179 in F. di Castri \& T. Younes, Biodiversity, Science and Development: Towards a New Partnership. CAB InterMountain Region of Southwestern Guyana. Conservation International, Washington, D.C.

Ehrlich, R. P. 1995. The scale of the human enterprise and biodiversity loss. Pp. 214-226 in J. Lawton \& R. M. May (editors). Extinction Rates. Oxford Univ. Press, Oxford.

Gdmez, R., A. Piva, A. Sittenfeld, E. Le6n, J. Jimenez \& G. Mirabelli. 1993. Costa Rica's conservation program and the National Biodiversity Institute (INBio). Pp. 5368 in W. Reid, A. Sittenfeld, S. Laird, D. Janzen, C. Meyer, M. GoUin, R. Gamez \& C. Juma (editors). Bio- 
diversity Prospecting: Using Genetic Resources for Sustainable Development. World Resources Institute, Washington, D.C.

Groombridge, B. 1992. Global Biodiversity Status of the Earth's Living Resources. World Conservation Monitoring Centre. Chapman \& Hall, London

Hernandez, F. 1790. Historia Plantarum Nov£e Hispaniae. In: Historia Natural de Nueva Espafia. 1960. Volumes I-III. Facsimile Edition, Universidad Nacional Aut6noma de Mexico. Mexico D.F. International Council for Bird Preservation (ICBP). 1992. Putting Biodiversity on the Map: Priority Areas for Global Conservation. International Council for Bird Preservation, Cambridge, United Kingdom.

Janzen, D. H. 1993. Taxonomy: Universal and essential national, Wallingford, United Kingdom. infrastructure for development and management of trop- Secretarfa de pesarrollo Social (SEDESOL). 1993. Reuical wildland biodiversity. Pp. 100-113 in 0. Terje \& P. J. Schei (editors), Proceedings of the Norway/UNEP Expert Conference on Biodiversity. Directorate for $\mathrm{Na}-$ 
ture Management, Trondheim, Norway.

, W. Hallwachs, R. Gtoez, A. Sittenfeld \& J. Ji-

menez. 1993. Research management policies: Permits

for collecting and research in the tropics. Pp. 131-157

ni6n sobre la mortandad de la mariposa monarca en

Mexico. Avdndaro, Mexico.

Sittenfeld, A. \& R. Gdmez. 1993. Biodiversity prospect-

ing by INBio. Pp. 69-67 in W Reid, A. Sittenfeld, S.

Laird, D. Janzen, C. Meyer, M. Gollin, R. Gamez \& C.

Juma (editors). Biodiversity Prospecting: Using Genetic

Resources for Sustainable Development. World Re-

sources Institute, Washington, D.C.

in W. Reid, A. Sittenfeld, S. Laird, D. Janzen, C. Meyer, c $\left.\right|^{\wedge}$ t $p$ t d' t i f i nno tu $c^{\wedge}:^{\wedge \wedge}$

_ _ ... ' i- o V- I V I- N T>- 1-• Sober6n, J. \& J. B. Llorente. 1993. the use ot species

M. Gollin, R. Gamez \& C. Juma (editors). Biodiversity

Prospecting: Using Genetic Resources for Sustainable

Development. World Resources Institute, Washington,

D.C.

Maddox, J. \& H. Gee. 1994. Mexico's bid to join the

Worid. Nature 368: 789-804.

Margules, C. R. \& M. P. Austin. 1995. Biological models 
accumulation functions for the prediction of species

richness. Conservation Biol. 7: 480-488.

Soto, M. \& A. G6mez-Pompa. 1990. Bioclimatologfa de

la Flora de Veracruz. No. 1. Institute de Ecologfa A.C., Xalapa, Mexico.

Soul6, M. (Editor). 1987. Viable Populations for Conservation. Cambridge Univ. Press, Cambridge.

for monitoring species decline: The construction and gtork, N. E. 1988. Insect diversity: Fact, fiction and spec-

use of databases. Pp. 183-196 in J. Lawton \& R. M.

May (editors), Extinction Rates. Oxford Univ. Press, Ox-

ford.

\& T. D. Redhead. 1995. BioRap. Guidelines for

ulation. Biol. J. Linn. Soc. 35: 321-337.

Systematics Agenda 2000 (SA2000). 1994. Systematics

Technical Re-

Using the BioRap Methodology and Tools. CSIRO,

Dickson, Australia.

Martfnez, E. \& C. H. Ramos. 1989. Lacandoniaceae

(Triuridales): Una nueva familia de Mexico. Ann. Mis-

souri Bot. Card. 76: 128-135. 
May R. M. 1990. How many species? Philos. Trans. Roy.

Soc. London, B330: 292-304.

Agenda 2000: Charting the Biosph

port by the Association of Systematics Collections, New

York.

Wheeler, Q. D. 1995. Systematics, the scientific basis for inventories of biodiversity. Biodiversity and Conservation 4: 476-4S9.

Whitmore, T C. \& J. A. Sayer. 1992. Tropical Deforestation and Species Extinction. Chapman \& Hall, London.

McNeely, J. A., K. R. Miller, W. V. Reid, R. MiUermeier Wilson, E. 0. 1992. The Diversity of Life. The Belknap \& T Werner. 1990. Conserving the Worlds Biological Diversity. International Union for the Conservation of Press of Harvard Univ. Press, Cambridge, Massachusetts. 
